\title{
PLANTEAMIENTOS DE POLÍTICA CRIMINAL EN MATERIA DE LESIONES DEPORTIVAS
}

\author{
Cristina Domingo Jaramillo \\ Contratada predoctoral FPU, Departamento de Derecho Penal, \\ Universidad de Granada \\ E-mail: cdomingo@ugr.es
}

\begin{abstract}
RESUMEN: el deporte, como institución dotada de su propia normativa y de organismos encargados de aplicarla a los individuos sujetos a su jurisdicción, ha pretendido erigirse con autonomía respecto del Ordenamiento Jurídico común. Esta situación plantea serios problemas cuando en el ámbito deportivo tiene lugar un ilícito pues surge la incertidumbre sobre cuál es la normativa a aplicar en ese caso, especialmente en cuanto a lesiones deportivas se refiere. En este sentido, a través de la revisión de la literatura y la jurisprudencia, el objetivo planteado en la presente investigación es delimitar la intervención del Derecho Penal para los casos de violencia endógena que derivan en resultados lesivos.
\end{abstract}

Palabras clave: lesiones deportivas, Derecho Penal, disciplina deportiva, bien jurídico.

\begin{abstract}
: sport, as an institution endowed with its own regulations and bodies in charge of appliying them to the individuals who are subject to its jurisdiction, has sought to establish itself with autonomy with respect to the common Legal System. This situation poses serious problems when an ilegal act takes place in the sports field, since uncertainty arises as to which is the regulation to apply in that case, especially with regard to sports injuries. In this sense, through the review of the literatura and the jurisprudence, the objective set out in this research consists in the delimitation of the intervention of Criminal Law in cases of endogenous violence that lead to harmful results.
\end{abstract}

Keywords: sports injuries, Criminal Law, athletic dicipline, legal right.

SUMARIO: I. Sobre LA PRETENDIDA aUtonomía deL Deporte fRente al ordenamiento JuRídico. 1.1. La disciplina deportiva y la prohibición de injerencia penal en el deporte. 1.2. Necesidad de intervención penal en materia deportiva. II. La eVentual responsabilidad penal por lesiones deportivas. 2.1. Coexistencia del Derecho Penal y la disciplina deportiva para la violencia endógena. 2.2. La virtualidad del principio non bis in idem. 2.3. Relevancia jurídico-penal de las lesiones deportivas. 2.3.1. Resultado lesivo sin infracción de las reglas del juego. 2.3.2. Infracción de las reglas que no causa lesión. 2.3.3. Lesiones ocasionadas con imprudencia. 2.3.4. Lesión intencionada sobrepasando la normativa deportiva. III. ConCLUSIONES. 


\section{SOBRE LA PRETENDIDA AUTONOMÍA DEL DEPORTE FRENTE AL ORDENAMIENTO JURÍDICO}

A simple vista, Derecho y deporte parecen ser dos materias cuya relación plantea problemas, siendo la misma, hasta hace poco tiempo, débil o inexistente. Esta situación de alejamiento entre estos dos ámbitos ha venido auspiciada por diversos motivos. Entre otros, por el hecho de que el deporte fue ignorado durante mucho tiempo como objeto de conocimiento científico y jurídico pues, en palabras de FERNÁNDEZ RODRÍGUEZ, "el intelectual español, en general, y el jurista en particular no se han dignado a descender desde el alto pedestal en que ellos mismos han pretendido situarse para estudiar el fenómeno deportivo, al que, al parecer, no reconocen dignidad bastante"1. La secular desatención por parte de los expertos derivó en la inexistencia de una disciplina especializada y ello, a su vez, en la escasez de estudios jurídicos en la materia ${ }^{2}$, de lo que se siguió la presencia de lo que se vino a denominar una "laguna respecto al estudio jurídico del deporte" 3 . Por otro lado, la creación de un marco normativo y la dotación de una estructura deportiva supranacional propia del deporte, conllevó el reconocimiento de su "especificidad" ${ }^{4}$ y multidisciplinariedad ${ }^{5}$, por lo que se erigió como una institución autónoma e independiente respecto del Ordenamiento Jurídico, resultando así lo que se ha venido a denominar, "complejo de isla" ${ }^{6}$ del deporte.

\subsection{La disciplina deportiva y la prohibición de injerencia penal en el deporte}

El alejamiento y la pretendida autonomía deportiva se hacen patentes con la prohibición de los deportistas y demás entes vinculados al entramado deportivo, de acudir a los tribunales ordinarios para resolver los conflictos surgidos en este ámbito. A título simplemente de ejemplo, la Carta Olímpica atribuye la potestad jurisdiccional en exclusiva a los órganos del Movimiento Olímpico que actúan en calidad de árbitro ante cualquier controversia surgida en el olimpismo, bajo pena de perder la licencia federativa. Tal prohibición también existe en el fútbol previéndose en los Estatutos de la FIFA, concretamente en el art. 59, donde se niega el derecho constitucional a la tutela judicial efectiva

1 FERNÁNDEZ RODRÍGUEZ, T.R., "Prólogo" a GARCÍA GRIMALDO, M.C., El Ordenamiento Jurídico del Deporte, Civitas, Madrid, 1974, p. 14.

2 RODRÍGUEZ-MOURULLO, A., y CLEMENTE, I., "Dos aspectos de Derecho penal en el deporte: el dopaje y las lesiones deportivas", Actualidad Jurídica. Uría Menéndez, no. 9, 2004, p. 53. A todo lo anterior, los autores añaden la falta de iniciativa de los deportistas de presentar ante los tribunales asuntos relativos a la práctica deportiva.

3 De esta opinión, RÍOS CORBACHO, J.M., Lineamientos de la violencia en el Derecho Penal del deporte, Reus, Madrid, 2019, p. 31.

4 GAMERO CASADO, E., "Bases estructurales del sistema deportivo", en Gamero Casado, E., (Coord.), Fundamentos de Derecho deportivo (Adaptado a estudios no jurídicos), Tecnos, Madrid, 2012, pp. 60 y ss.

$5 \mathrm{Ibd}$., p. 60, el citado autor entiende que representa un corte transversal en el ordenamiento, afectando a muchas ramas jurídicas diferentes, entre las que se encuentra, como es lógico, el Derecho Penal. En términos similares, DE VICENTE MARTÍNEZ, R., Derecho Penal del deporte, Bosch, Barcelona, 2010, p. 53, cuando afirma que el deporte se caracteriza por la interdisciplinariedad, debido a que la práctica deportiva conlleva la realización de conductas que en muchas ocasiones rozan o traspasan los límites de la legalidad, afectando transversalmente a las distintas ramas del Derecho.

6 Véase, CAZORLA PRIETO, L.M., Deporte y Estado, Revista Aranzadi de Deporte y Entretenimiento, Navarra, 2012. p. 70. La expresión fue acuñada por el citado autor en una obra con el mismo título que la anterior, en el año 1979. 
a los futbolistas y demás individuos ligados al sistema deportivo ${ }^{7}$. En nuestro país, este escenario de exclusión jurisdiccional fue fomentado por la legislación de la época y la estructura administrativa del periodo dictatorial, de carácter piramidal e incrustado en el Estado, supervisor de las decisiones aplicadas en materia deportiva ${ }^{8}$. En dicho sentido, el art. 76 del Estatuto Orgánico de la Antigua Delegación Nacional de Educación Física y Deportes prohibía expresamente a los deportistas y sociedades acudir a otra disciplina o poder distinto de la susodicha Delegación para resolver sus problemas, so pena de pérdida de la condición que ostentaren o descalificación automática.

Por fortuna, esta situación cambió en el año 1978 con la entrada en vigor de la Constitución Española, momento en el que los poderes públicos adquirieron competencia en materia deportiva a través del mandato de fomento al legislador contenido en el art. 43.3. A partir de entonces, el deporte, de naturaleza pública, deja de contemplarse como un ámbito exclusivamente privado, pudiendo la jurisdicción ordinaria conocer de las controversias deportivas. A pesar de ello, la situación no cambió en lo esencial porque desde sus inicios, el deporte generó mecanismos de resolución de conflictos alejados de la legislación ordinaria ${ }^{9}$. De este modo, se fue proveyendo de su propia competencia jurisdiccional, dotada a su vez de mecanismos de autorregulación en manos de las federaciones deportivas, en el ejercicio de la disciplina deportiva ${ }^{10}$ a través de unas funciones públicas delegadas por la Administración. Por tanto, el deporte se alejó del sistema normativo común desde el momento en el que pretendió extender la función de los reglamentos deportivos más allá de la propia organización federativa, haciéndose extensible al resto del orden jurisdiccional, al excluir cualquier otra sanción distinta de la disciplinaria, de forma que ésta supusiera el bloqueo de la aplicación del Derecho Penal.

$7 \quad$ Así, el apartado segundo del citado precepto señala que "queda prohibida la vía del recurso ante los tribunales ordinarios, a menos que se especifique en la reglamentación de la FIFA. Queda excluida igualmente la vía ordinaria en el caso de medidas cautelares de toda índole". Esto se debe al compromiso de reconocer al Tribunal Arbitral del Deporte (TAD) como autoridad judicial independiente (por lo que sus sentencias han de acatarse) y, a la prohibición expresa de acudir a los tribunales ordinarios, debiéndose prever, por el contrario, procedimientos arbitrales, sometidos a un tribunal independiente. Y, en caso de incumplimiento de dicha obligación, las federaciones impondrán las sanciones pertinentes a quien corresponda.

8 CARRETERO LESTÓN, J.L., "La violencia deportiva en el Derecho español: antecedentes, régimen actual y distribución de competencias", en Millán Garrido, A., (Coord.), Régimen jurídico de la violencia en el deporte, Bosch, Barcelona, 2006, p. 173. Para profundizar más en la evolución del acceso a la justicia ordinaria en el ámbito deportivo, JIMÉNEZ SOTO, I., "El impulso democratizador de la Ley General de la Cultura Física y el Deporte de 1980", en De La Plata Caballero, N., (Dir.), Las leyes del deporte de la democracia: Bases para una Ley del siglo XXI, Dykinson, Madrid, 2002, pp. 21 y ss.

9 Esto ha sido denominado por algunos autores como "ámbito jurídico libre". Véase, por todos, MORILLAS CUEVA, L., "Derecho y deporte. Las múltiples formas del fraude en el deporte”, en Morillas Cueva, L., (Dir.), Respuestas jurídicas al fraude en el deporte, Dykinson, Madrid, 2017, p. 13, si bien el citado autor rechaza completamente la anterior hipótesis. Esta situación también ha sido calificada como una "huida de la jurisdicción ordinaria" por COLOMER HERNÁNDEZ, I., "Doctrina del Tribunal Federal Suizo de Derecho Civil sobre la voluntad exigible a los deportistas para la renuncia a la jurisdicción ordinaria y la utilización de mecanismos de justicia deportiva en la solución de conflictos", Revista Aranzadi de Derecho de Deporte y Entretenimiento, nº. 20, 2007, p. 271.

10 Las federaciones son entes privados formados por organizaciones de la misma naturaleza -como los clubes deportivos-. Sin embargo, al estar creados por una resolución del Consejo Superior de Deportes (CSD), se les suele atribuir carácter público pues ejercen por delegación funciones de esta índole. Por dicho motivo, estamos de acuerdo con CARRETERO LESTÓN en la naturaleza "semipública" de tales entes: "La violencia deportiva en el Derecho español...", cit., p. 172. Para profundizar acerca de la disciplina deportiva, véase el análisis efectuado sobre la materia por RODRÍGUEZ TEN, J., "El régimen disciplinario del deporte", en Palomar Olmeda, A., (Dir.,), Derecho del deporte, Aranzadi, Pamplona, 2013, pp. 754 y ss. 


\subsection{Necesidad de intervención penal en materia deportiva}

A pesar de la propensión de alejar el deporte del Derecho, aquel como toda actividad social, debe someterse a lo establecido en el Ordenamiento Jurídico cuando surjan cuestiones que excedan el ámbito de actuación de la disciplina deportiva y, de un tiempo a esta parte, se ha dedicado mayor atención a los aspectos jurídicos que pivotan en torno al deporte, implicándose los juristas cada vez más en su estudio ${ }^{11}$, de la misma forma que es más frecuente la intervención de los distintos sectores jurisdiccionales en la resolución de las cuestiones deportivas $^{12}$. No obstante, ello no viene a significar la justificación de toda injerencia jurídica en el deporte, pues ha de reconocerse cierta autonomía a la disciplina deportiva, al menos en lo concerniente a la aplicación de los reglamentos y la organización de cada actividad, de modo que las demás cuestiones que excedan de este ámbito deben ser conocidas por el sector jurisdiccional que en su caso corresponda. En este sentido se posiciona parte de la doctrina que sostiene la necesidad de conciliar Derecho y deporte ${ }^{13}$. Asimismo, a nuestro juicio, existe un Derecho disciplinario deportivo encargado de dirimir las cuestiones exclusivamente deportivas, pero ello no viene a significar la total exclusión del deporte del sistema jurídico común. Este último puede y debe intervenir en todas aquellas cuestiones que requieren la intervención de alguno de sus sectores. Por tanto, la autosuficiencia de la organización deportiva se justifica en lo estrictamente deportivo, es decir, en las cuestiones relativas a la organización deportiva y aquellas que suponen una infracción de las reglas de juego ${ }^{14}$. Esta última cuestión trae causa de la inmediatez con la que se desarrolla la competición, lo cual viene a justificar la aplicación urgente de sus reglas, debiendo el árbitro imponer al momento la sanción que, en su caso, corresponda.

Por tanto y, para culminar, reincidir en la necesidad de que el sistema normativo deportivo y el Ordenamiento Jurídico común, coexistan. Esto no plantea especial problema para algunos delitos que tienen lugar en el deporte, como ocurre con la corrupción, el dopaje y los desórdenes públicos ${ }^{15}$, no así para la violencia endógena (o cometida por los propios deportistas durante el transcurso de un encuentro o competición), para la cual se suele considerar suficiente la imposición de una sanción proveniente del ámbito disciplinario deportivo cuando los resultados derivados de la misma son en

11 Algunos motivos que justifican la mayor atención doctrinal al deporte son la influencia de los fenómenos sociales y culturales en las instituciones y, por ende, en el Derecho; la profesionalización deportiva; su exagerada comercialización; el aumento de grandes competiciones internacionales y de los individuos consagrados a la actividad deportiva; y el impulso del deporte por la Administración: CARRETERO LESTÓN, J.L., "Consideraciones históricas sobre la fundamentación del Derecho deportivo", Anuario Iberoamericano de Derecho deportivo, $\mathrm{n}^{\circ}$. 1 , 2009, p. 22.

12 MORILlas CUEVA, L., "Derecho Penal y deporte", Revista Andaluza de Derecho Deportivo, n. 1, 2006, p. 36; RÍOS CORBACHO, J.M., Lineamientos de la violencia en el Derecho Penal del Deporte..., cit., p. 31. Así, debe actuar tanto el ámbito penal como otras disciplinas, porque no existen solamente problemas punitivos, también cuestiones que afectan a otros ámbitos del orden jurisdiccional. En dicha línea, MAJADA PLANELLES, A., El problema penal de la muerte y las lesiones deportivas, Bosch, Barcelona, 1946, pp. 1 y 2.

13 Entre otros, MORILLAS CUEVA, L., "Derecho y deporte. Las múltiples formas del fraude en el deporte...", cit., pp. 14 y ss.

14 De esta opinión, FERNÁNDEZ RODRÍGUEZ, T.R., La justicia deportiva. Cuatro estudios, Civitas, Navarra, 2015 , pp. 31 y 32. Ello trae causa de la inmediatez del juego, lo cual viene a justificar la aplicación urgente de las reglas del mismo, debiendo el árbitro imponer al momento la debida sanción.

15 De hecho, estas acciones se encuentran expresamente tipificadas en el Código Penal. Así, la corrupción se ubica en el apartado cuarto del art. 286 bis CP, el delito de dopaje en el 362 quinquies CP y la violencia exógena en los arts. 557 a $559 \mathrm{CP}$. 
muchas ocasiones de tal gravedad que ameritarían el oportuno reproche penal. Es cierto que el Ordenamiento punitivo no puede conocer de todas las lesiones que tengan lugar entre deportistas en tanto en cuanto ello conllevaría una criminalización del deporte que podría acabar con algunas prácticas deportivas, pero tampoco puede quedar extramuros del deporte. El Estado debe intervenir en este caso, puesto que tal como apunta MORILLAS CUEVA, no puede renunciar a la obligación constitucional de salvaguardar bienes jurídicos fundamentales, dejando espacios "ajurídicos" bajo responsabilidad de otras regulaciones poco formales y no estatales ${ }^{16}$. En vista de la complejidad que plantea la incriminación de las lesiones deportivas, en lo siguiente se abordará la tarea de delimitar la intervención punitiva en las mismas, teniendo además en consideración el ámbito de actuación de la disciplina deportiva.

\section{LA EVENTUAL RESPONSABILIDAD PENAL POR LESIONES DEPORTIVAS}

Como venimos señalando, la disciplina deportiva ha negado tradicionalmente la entrada a la actuación punitiva en el deporte, especialmente en el caso de las lesiones, lo cual ha propiciado la impunidad de muchos incidentes de este tipo que por sus características serían acreedores de intervención penal, por lo que el deporte ha sido considerado tradicionalmente un espacio que escapaba del Derecho Penal ${ }^{17}$, llegándose incluso a afirmar que "el propio Derecho Penal se detiene ante los muros de un estadio deportivo"18 o "lo que sucede en el campo se queda en el campo"19. De este modo, hechos que en cualquier otro entorno social sufren las consecuencias, incluso de la mayor severidad, de este sector, siempre y cuando cumplan los requisitos jurídicamente necesarios para ello, si tienen lugar en el deportivo suelen estar exentos de responsabilidad criminal, a lo que debemos añadir la falta de iniciativa de los deportistas a acudir a los tribunales penales por asuntos relativos a su actividad, siendo la solución más frecuente la vía administrativa/deportiva

16 MORILLAS CUEVA, L., "Derecho Penal y deporte...", cit., p. 37; en este sentido, conviene recordar que la potestad disciplinaria deportiva la ejercen en su mayoría las federaciones, como entes privados (o semipúblicos) dotados de cierta autonomía por la Administración. De forma parecida, PAREDES CASTAÑÓN, J.M., "La responsabilidad penal del deportista: el ejemplo del boxeador", Revista Española de Derecho Deportivo, Civitas, Madrid, $n^{\circ} .5,1995$, p. 81, argumenta que no hay razón para justificar que las conductas deportivas deban quedar al margen del instrumento último de protección de los intereses más importantes.

17 DE VICENTE MARTÍNEZ, R., Derecho Penal del deporte..., cit., p. 90. Esto es así porque el legislador, en un primer momento, no entendió conveniente acudir al Derecho Penal en cuestiones deportivas, a lo que se unía la tendencia a estructurar marcos jurídicos específicos y autónomos para las competiciones deportivas; pero no solo el deporte estaba alejado del Derecho Penal, sino (como se ha expuesto supra) también del resto de ramas del orden jurisdiccional. Situación de aislamiento de la que afortunadamente ya se está saliendo. En este sentido, véanse entre otros, ESER, A., "Lesiones deportivas y Derecho Penal: en especial, la responsabilidad del futbolista desde una perspectiva alemana", La Ley, nº. 2499, 1990, p. 1; CUCHI DENIA, J.M., "La incidencia del Derecho Penal en la disciplina deportiva: la aplicación del principio non bis in idem", Revista Española de Derecho Deportivo, Edt., Civitas, Madrid, no. 8, 1997, p. 15; y MORILLAS CUEVA, L., "Derecho y deporte. Las múltiples formas del fraude en el deporte...", cit., pp. 12 y ss. Ilustrativa de esta situación de impunidad es la frase "la tiza que rayaba la cancha de los estadios, o las cuerdas de un cuadrilátero, eran la más completa y total eximente de responsabilidad penal”, acuñada por SALIM-HANNA SEPÚLVEDA en El fútbol y la violencia, 2 de agosto de 2004, artículo sin paginar, recurso electrónico obtenido a través de la Web: http://www.belt.es/articulos/ HOME2 articulo.asp?id=2095, recuperado el día 15 de noviembre de 2021.

18 FERNÁNDEZ RODRÍGUEZ, en el Prólogo a García Grimaldo..., cit., p. 15.

19 RODRÍGUEZ-MOURULlO, A., y CLEMENTE, I., “Dos aspectos de derecho penal en el deporte...”, cit., p. 65. 
para arreglar sus disputas ${ }^{20}$. Por otra parte, existe una amplia aceptación de la violencia deportiva, llegando algunas acciones a ser aceptadas y consideradas normales dentro de la dinámica de la competición. En dicho sentido, ante una grave agresión en el terreno de juego con nefastas consecuencias, los espectadores suelen permanecer impasibles ante tamaño desprecio por la salud del deportista, llegando en ocasiones a solicitar más violencia por parte de los jugadores, pero debemos reseñar que, aunque existe un tipo de violencia permitida y reglamentaria, hay otra que sobrepasa toda prescripción normativa, por lo que los mecanismos federativos no serían suficientes para exigir responsabilidad al individuo agresor.

\subsection{Coexistencia del Derecho Penal y la disciplina deportiva para la violencia endógena}

La anterior situación está cambiando en tanto se aprecia un acercamiento entre deporte y Derecho Penal en cuanto a violencia endógena se refiere y los atletas parecen no mostrarse tan remisos a dirimir sus conflictos en el orden punitivo ${ }^{21}$. Sin embargo, parte de la doctrina continúa considerando suficientes los instrumentos disciplinarios deportivos para solucionar los litigios que tienen lugar en este entorno, incluso cuando la lesión tiene lugar fuera de un lance del juego y con clara infracción de las reglas del mismo ${ }^{22}$. A nuestro juicio y, siguiendo a CARRETERO LESTÓN, entendemos que cuando un deportista trasgrede lo establecido en la reglamentación deportiva y realiza una conducta que está sólo ocasionalmente vinculada con la práctica deportiva, estamos ante un delito cuyo conocimiento supera la competencia federativa ${ }^{23}$. Así, la justicia penal ha de intervenir en los hechos violentos que alcanzan la consideración de delito, aunque normalmente su abstención viene justificada por tener lugar en la práctica de un deporte, como si éste estuviera excluido del Ordenamiento Jurídico. Sí es cierto que la violencia endógena cuenta con un tratamiento normativo específico, pues los límites de su ejercicio vienen precisados en la reglamentación de cada actividad, por lo que todas las conductas que sobrepasen tales términos y derivan en una conculcación flagrante del bien jurídico tutelado, justifican la intervención penal.

$20 I b d$., 53. En términos similares pero en mayor profundidad, PAREDES CASTAÑÓN pone de manifiesto que los tribunales tradicionalmente han mostrado reticencias a entrar en el terreno deportivo, en "Consentimiento y riesgo en las actividades deportivas: algunas cuestiones jurídico-penales", Anuario de Derecho penal y Ciencias Penales, Tomo 43, 1990, p. 635; EL MISMO en un análisis posterior continúa argumentando que la ausencia de estudio específico que reclama la problemática delictiva cuando se produce en el ámbito deportivo, ha sido la regla general hasta hoy, lo cual se ha traducido en la situación general de impunidad: "La responsabilidad penal del deportista: el ejemplo del boxeador", Revista Española de Derecho Deportivo, Civitas, Madrid, nº. 5, 1995, p. 82. Además, en pocas ocasiones los deportistas acuden a la justicia penal aunque una acción revista los caracteres de delito, quedando la cuestión en manos de la jurisdicción deportiva. En este sentido, DOMÍNGUEZ IZQUIERDO, E.M., "El consentimiento y la relevancia penal de los resultados lesivos en los deportes de contacto eventualmente violentos: el caso del fútbol”, en Morillas Cueva, L., y Mantovani, F., (Dirs.) y Benítez Ortúzar, I.F., (Coord.), Estudios sobre Derecho y Deporte, Dykinson, Madrid, 2008, p. 125. En la misma línea, RÍOS CORBACHO, J.M., Lineamientos de la violencia en el Derecho Penal del deporte..., cit., p. 36.

21 MORILLAS FERNÁNDEZ, D.L., "La violencia en los espectáculos deportivos", Revista Andaluza de Derecho del Deporte, no. 6, 2009, p. 40; y GAMERO CASADO, E., "Violencia en el deporte y violencia en espectáculos deportivos: referencia histórica y problemática actual", en Millán Garrido, A., (Dir.) Régimen jurídico de la violencia en el deporte, Bosch, Barcelona, 2006, p. 20.

22 En este sentido, véase PAREDES CASTAÑÓN, J.M., "Consentimiento y riesgo en las actividades deportivas...", cit., p. 637.

23 CARRETERO LESTÓN, J.L., "La violencia deportiva en el Derecho español...”, cit., p. 117. 
En muchas ocasiones se producen solapamientos entre ambos sistemas normativos, de modo que se hace difícil concretar cuál de ellos debe intervenir o si es posible que los dos desplieguen su eficacia. Esto último, en un primer momento, parece no poder tener lugar en base a la conculcación del principio non bis in idem, que adquiere especial relevancia en este caso ${ }^{24}$ pues, como decimos, muy frecuentemente el Derecho Penal y la disciplina deportiva entran en conflicto en el momento en que pueden intervenir en un determinado supuesto.

\subsection{La virtualidad del principio non bis in idem}

Cuando cabe aplicar lo dispuesto por los sistemas normativos indicados, la competencia en primera instancia corresponde al ámbito deportivo, debiendo el Derecho Penal intervenir únicamente cuando la vulneración de los bienes jurídicos fundamentales sea de especial intensidad y, en última instancia, cuando los mecanismos previos, menos gravosos, hayan fracasado, por los principios de intervención mínima y subsidiariedad que rigen en este ámbito ${ }^{25}$. Por lo general, no queda claro qué normativa debe imponerse en cada caso, dando lugar a supuestos de concurrencia de varias sanciones y además nos encontramos con el principio non bis in idem que proscribe un doble enjuiciamiento siempre que concurra identidad de hecho, sujeto y fundamento.

Centrándonos en el tercer criterio de los señalados para que el non bis in idem tenga virtualidad, es decir, la necesidad de que ambas sanciones difieran en su fundamento, el art. 38.1 de la Ley 19/2007, de 11 de julio, contra la Violencia, el Racismo, la Xenofobia y la Intolerancia en el deporte (en adelante, LCVD), concreta que "sólo podrá recaer sanción penal y administrativa y disciplinaria sobre los mismos hechos cuando no hubiera identidad de fundamento jurídico". En dicha línea, COLOMER HERNÁNDEZ delimita los casos en los que el principio non bis in idem no tiene eficacia y, por ello, cabe la imposición de doble sanción en materia deportiva: a) identidad de sujeto pasivo; b) identidad de hechos; c) diversidad de procedimientos sancionadores o, lo que es lo mismo, que haya un proceso penal ya iniciado; y d) diversidad de fundamento (o bien jurídico) ${ }^{26}$.

En este sentido, debemos reseñar que la disciplina deportiva tiene como finalidad investigar, comprobar y corregir o sancionar los incumplimientos y transgresiones a la reglamentación deportiva imputables a las personas (tanto físicas como jurídicas) sometidas al sistema deportivo ${ }^{27}$, mientras que el Derecho Penal se dirige a salvaguardar los

24 La normativa deportiva recoge en varios preceptos este principio. Así, está previsto en la letra b) del art. 75 de la Ley 10/1990, de 15 de octubre, del Deporte cuando alude expresamente a la "inexistencia de doble sanción por los mismos hechos" como una de las disposiciones estatutarias o reglamentarias que habrán de preverse por los Clubes deportivos que participen en competiciones de ámbito estatal, Ligas Profesionales y Federaciones deportivas españolas. Igualmente, el apartado tercero del art. 8 del RD 1591/1992, de 23 de diciembre, sobre Disciplina Deportiva, aunque según establece el art. 27.2 del mismo cuerpo normativo, cabe la imposición de doble sanción para una misma infracción, siempre y cuando sean de distinta naturaleza y estén previstas para la concreta categoría y que, en su conjunto, sean congruentes con la gravedad de la misma.

25 MORILlas CUEVA, L., Sistema de Derecho Penal. Parte General, Dykinson, Madrid, 2018, pp. 134 y 135.

26 COLOMER HERNÁNDEZ, I., "Relaciones entre proceso penal y procedimientos sancionadores y disciplinarios en materia de violencia en el deporte", en Palomar Olmeda, A., y Gamero Casado, E., (Coords.), Comentarios a la Ley contra la Violencia, el Racismo, la Xenofobia y la Intolerancia en el Deporte, Aranzadi, Navarra, 2008, pp. 519-552.

27 BARBA SÁNCHEZ, R., "La prevención de la violencia, el racismo, la xenofobia y la intolerancia en el deporte. La seguridad en los estadios”, en Palomar Olmeda, A., (Dir.) y Terol Gómez, R., (Coord.), Derecho del Deporte Profesional, Aranzadi, Navarra, 2017, pp. 766 y 767. 
bienes jurídicos fundamentales para garantizar la adecuada convivencia social, por lo que el fundamento de ambas sanciones difiere. Por tanto, el sistema disciplinario deportivo se centra en salvaguardar el correcto desarrollo de la competición y el Penal, el bien jurídico salud del deportista. La jurisprudencia se manifiesta en tales términos, de modo que la SAP de Baleares 268/2001 de 31 de diciembre, [JUR/2002/70009] que trae causa de unas lesiones ocurridas durante un partido de fútbol, previamente sancionadas en vía deportiva, sostiene que "ambas sanciones no son incompatibles porque una cosa es el mantenimiento de determinadas reglas deportivas en los encuentros, que corresponde a los órganos administrativos y otra muy distinta es erradicar acciones dolosas netamente agresivas, como puñetazos al contrario, aunque sea para impedir su triunfo" ${ }^{28}$. No solo la jurisprudencia, también la doctrina mayoritaria, al considerar posible la acumulación de pena y sanción deportiva en la violencia endógena, al ser los bienes jurídicos tutelados por los sistemas punitivo y disciplinario, distintos ${ }^{29}$.

Asimismo, teniendo la sanción de cada sistema normativo diferente fundamento, pueden desplegar sus efectos por un mismo supuesto que requiera la intervención de ambos sin conculcar por ello el principio non bis in idem $^{30}$. Sin embargo, a pesar de que el Derecho Penal puede -y debe- conocer las lesiones deportivas que así lo requieran aunque haya recaído previamente una sanción de tipo deportivo, tanto doctrina como jurisprudencia han establecido una serie de teorías que justifican la no intervención punitiva en las lesiones deportivas: de la costumbre, de la adecuación social, del fin reconocido por el Estado, de las normas de cultura, de la inexistencia de figura delictiva, del consentimiento, del derecho profesional, del riesgo permitido, del móvil contrario a derecho y

28 En este sentido, véase también la SAP de Madrid 405/2002 de 13 de diciembre, [JUR/2003/82451] en la cual se sostiene la no vulneración del principio non bis in idem porque los ámbitos de enjuiciamiento y las sanciones están claramente separados y con fundamentos distintos. Uno meramente disciplinario en el ámbito deportivo, tutelando la paz deportiva y sancionando sus alteraciones y el enjuiciamiento penal que tutela y sanciona el atentado contra la integridad; y, de forma similar las SSAP de Las Palmas 46/2006 de 20 de enero, [JUR/2006/100580]; de Pontevedra 17/2003 de 30 de junio, [JUR/2004/2952]; y de Girona 41/2009 de 16 de enero, [JUR/2009/142628]. Esta última fundamenta que, "aunque los hechos son los mismos, como han sido normativamente evaluados desde perspectivas distintas la doble sanción penal y administrativa resulta compatible, no produciéndose la denunciada vulneración del principio". Anteriormente, en el mismo sentido, la STS de 1 de junio de 1951 en la que se condena un delito de lesiones a pesar de que la federación se había pronunciado antes, imponiendo previamente una sanción disciplinaria.

29 CUCHI DENIA, J.M., "La incidencia del Derecho Penal en la disciplina deportiva...", cit., pp. 172 y 173; VENTAS SASTRE, R., "La violencia en el deporte: tratamiento en el Derecho Penal español", Letras Jurídicas: Revista Electrónica de Derecho, no. 5, 2007, pp. 11 y 12. Esta última autora en cita sostiene que el Derecho Penal debe aplicar su carácter vinculante también al deporte. De este modo, la aplicación de sanciones deportivas no excluye la posibilidad de que la jurisdicción penal pueda también imponer una pena, sin que esta duplicidad vulnere el non bis in idem, puesto que el bien jurídico difiere; PIÑEIRO SALGUERO, J., Responsabilidad civil y deporte, Tesis doctoral, Universitat Pompeu Fabra, Barcelona, 2008, p. 145; y RÍOS CORBACHO, J.M., Lineamientos de la violencia en el Derecho Penal del deporte..., cit., p. 246.

30 MORILlAS CUEVA, L., "Derecho y deporte. Las múltiples formas del fraude en el deporte...", cit., p. 17; BENÍTEZ ORTÚZAR, I.F., "Derecho Penal y deporte en España. Especial referencia a la actividad violenta y a la actitud racista y xenófoba", Revista Andaluza de Derecho del Deporte, nº. 4, 2008, pp. 56 y ss., para el último, es necesario huir de posiciones extremas, con el objetivo de conseguir el necesario equilibrio entre la esencial existencia de un Derecho deportivo autónomo que regule la responsabilidad deportiva y, el Derecho Penal, que no puede abandonar su función de protección de bienes jurídicos; TERRADILLOS BASOCO, J.M., “¿Qué fair play? ¿Qué deporte?", Fair Play, vol. 1, n. 1, 2013, pp. 53 y 54, de forma parecida, señala que las reglas del fair play despliegan su eficacia en el terreno de juego para asegurar los fines y las características de la práctica deportiva, pero no derogan normas punitivas de rango superior que, con función distinta, tutelan bienes jurídicos distintos a los intereses implicados en el juego. 
de la acción consciente a riesgo permitido ${ }^{31}$. Tales teorías no pueden excluir la responsabilidad penal por lesiones deportivas en todo caso. La casuística es muy diversa y no todos los supuestos merecen respuesta penal del mismo modo que no todas las lesiones deportivas deben conocerse únicamente por la disciplina deportiva, siendo en no pocas ocasiones muy difícil concretar el ámbito de actuación de cada uno de estos dos sistemas normativos. Por dicho motivo, a continuación nos proponemos exponer las acciones y resultados más comunes que se derivan de la práctica deportiva, indicando la respuesta que, a nuestro entender, sería más adecuada en aplicación de las teorías anteriormente señaladas.

\subsection{Relevancia jurídico-penal de las lesiones deportivas}

Los resultados lesivos que tienen lugar en el deporte se caracterizan por su heterogeneidad, difiriendo en formas de presentarse, intensidad y consideración de ilícitos en función de la modalidad. Algunas se basan en el contacto físico entre contendientes (como el fútbol o el baloncesto) y otras en la violencia (entre las que se encuentra el boxeo o las artes marciales mixtas). Por este motivo, en el deporte se tolera un nivel de violencia superior al del resto de la sociedad, por lo que se ha de ser cauteloso a la hora de justificar la intromisión penal en el entramado deportivo porque si se llegase a perseguir penalmente cualquier infracción reglamentaria con resultado lesivo, aun siendo de escasa gravedad, el jugador estaría obligado a evaluar constantemente la posible peligrosidad de sus acciones, lo cual podría conllevar una alteración del normal desarrollo del juego ${ }^{32}$. De hecho, lo que hace interesante a la actividad deportiva es que el individuo sobrepase el límite de la prudencia para conseguir la gesta deportiva ${ }^{33}$. De modo que la punición de cualquier lesión podría conllevar, como señalamos en líneas superiores, una criminalización del deporte y provocaría que muchos jugadores se mostraran remisos a practicar algunas actividades si su actuación, casi con total seguridad, fuera perseguible penalmente. Así las cosas, delimitar con precisión el ámbito punible del impune es una tarea difícil por el componente competitivo y el esfuerzo por lograr la victoria, motivos que obligan a la asunción por parte del deportista de un riesgo mayor al socialmente permitido.

Cada deporte tiene su propia normativa en la que se regula el nivel de violencia aceptado y los supuestos son muy diferentes según nos encontremos ante un tipo de actividad u otro. Además, son muchos los presupuestos teóricos esgrimidos para fundamentar la exención de responsabilidad penal del deportista que lesiona al contrincante y ninguno de ellos puede articularse como solución única a esta cuestión, pues se trata por lo general de construcciones monistas que utilizan un solo criterio, sin considerar la diversidad de situaciones que pueden tener lugar, al tiempo que muchos de ellos son reiterativos en sus planteamientos y poco convincentes ${ }^{34}$. Por tanto, se requiere de una propuesta múltiple para poner solución a esta problemática, teniendo también en consideración los distintos y muy variados supuestos que en la práctica pueden tener lugar.

31 MORILLAS CUEVA, L., "Derecho Penal y deporte...", cit., pp. 43 y 44.

32 En este sentido se pronuncia FONTÁN TIRADO, R., "Notas a la problemática sobre lesiones deportivas en el Derecho Penal inglés y español”, Revista de Derecho Penal y Criminología, no. 5, 1995, p. 296.

33 VALLS PRIETO, J., "La intervención del Derecho Penal en la actividad deportiva", Revista Electrónica de Ciencia Penal y Criminología, vol. 11, $\mathrm{n}^{\circ} .14,2009$, p. 7.

34 De esta opinión, MORILLAS CUEVA, L., "Derecho Penal y deporte...”, cit., p. 4. 


\subsubsection{Resultado lesivo sin infracción de las reglas del juego}

El respeto a la reglamentación deportiva constituye el parámetro de licitud de las lesiones deportivas ${ }^{35}$, puesto que las reglas marcan el límite de la impunidad. Asimismo, su violación se erige condición necesaria para la intervención judicial, pues al despreciarse o transgredirse, las lesiones se convierten en dolosas y, en dicho caso, nunca podrán encontrar justificación ${ }^{36}$. En sentido contrario, a quien actúa conforme al reglamento pero lesiona al contrincante no puede imputársele como autor de un delito de lesiones. Ello ha de ser así porque sería contradictorio que el reglamento permitiese una conducta y el Derecho Penal la sancionase ${ }^{37}$. La doctrina se muestra unánime sobre la no injerencia del ámbito punitivo para las lesiones ocasionadas respetando la normativa deportiva, dividiéndose en los partidarios de la atipicidad de la conducta ${ }^{38}$, esgrimiendo los argumentos de la adecuación social y el riesgo permitido; y, aquellos que defienden la exclusión de la antijuridicidad de la misma a través de la causa de justificación del ejercicio legítimo de un derecho, oficio o cargo del art. $20.7 \mathrm{CP}^{39}$.

En lo relativo a la adecuación social, que una conducta sea considerada como adecuada socialmente viene a determinar su atipicidad. Ciertas actividades peligrosas deben ser lícitas en base a su utilidad social, siempre y cuando converjan tres elementos fundamentales: tolerancia, escasa gravedad y beneficio social de la conducta ${ }^{40}$. Entre tales actividades, se encuentra el deporte. En este caso, si la acción del deportista que lesiona a otro es adecuada socialmente, es decir, se ajusta a lo establecido reglamentariamente y no sobrepasa los límites tolerados, es atípica. No obstante, este presupuesto teórico presenta serios problemas dada su vaguedad jurídico-penal, pues no especifica qué es lo que se considera socialmente adecuado. Así, siguiendo a MORILLAS CUEVA, podemos afirmar que el mismo es ambiguo ${ }^{41}$. Por este motivo, se hace necesario buscar otras fórmulas más adecuadas y menos confusas.

35 DE VICENTE MARTÍNEZ, R., Derecho Penal del deporte..., cit., p. 147; GARCÍA VALDÉS, C., "El Derecho Penal y disciplinario en la Ley del Deporte", Cuadernos de Política Criminal, nº. 39, 1989, pp. 976 y 977 sostiene que si la lex artis no se respeta y existe agresión clara al margen de lo establecido reglamentariamente y del riesgo aceptado, ha de reconocerse la reprochabilidad de la conducta, ya sea penal o administrativa, a título de dolo o imprudencia; VENTAS SASTRE, R., "La tutela penal”, en Palomar Olmeda, A., y Gamero Casado, E., (Coords.), Comentarios a la Ley contra la Violencia, el Racismo, la Xenofobia y la Intolerancia en el Deporte, Aranzadi, Navarra, 2008, p. 579; y MORILLAS FERNÁNDEZ, D.L., "La justificación de las lesiones deportivas", en Morillas Cueva, L., y Mantovani, F., (Dirs.) y Benítez Ortúzar, I.F., (Coord.), Estudios sobre Derecho y deporte, Dykinson, Madrid, 2008, p. 122.

36 NAVAS RENEDO, B., "Las reglas de juego como límite a la intervención del Derecho Penal”, en Millán Garrido, A., (Coord.), Régimen jurídico de la violencia en el deporte, Bosch, Barcelona, 2006, p. 331.

37 Esta situación constituiría, a juicio de LOAYZA GAMBOA, una "anomia jurídico penal", dado que una misma acción no puede estar permitida y a la vez prohibida por distintos sectores del Derecho: "Justificación de las lesiones y violencia en los deportes. Un análisis penal de los deportes violentos como el fútbol”, Revista Digital, $\mathrm{n}^{\circ} .95,2006$, recurso digital obtenido a través de la Web: http://www.efdeportes.com/efd95/penal.htm, recuperado el día 20 de mayo de 2021.

38 Entre ellos, DE VICENTE MARTÍNEZ, para quien la ausencia de responsabilidad penal en este caso trae causa de la atipicidad de la conducta, aunque pueda ser ofensiva al bien jurídico, por carecer de los elementos mínimos de la culpa, puesto que no hay dolo sin culpa: Derecho Penal del deporte..., cit., p. 149. En supuestos de este tipo, existe una violación de la regla cautelar pero ejecutada dentro del umbral mínimo de tipicidad.

39 Cfr. BENÍTEZ ORTÚZAR, I.F., "Derecho Penal y deporte en España...”, cit., pp. 59 y 60.

40 FONTÁN TIRADO, R., "Notas a la problemática sobre lesiones deportivas en el Derecho Penal inglés y español...", cit., pp. 273 y 274.

41 MORILlAS CUEVA, L., "Derecho Penal y deporte...”, cit., p. 45. EL MISMO, en Sistema de Derecho Penal. Parte General..., cit., p. 471-473. En este último afirma que es poco aceptable que una misma conducta esté socialmente aceptada y a la vez contenida en un tipo penal. 
En dicho sentido, con la pretensión de subsanar las deficiencias de la anterior, surge la teoría del riesgo permitido, la cual plantea que cualquier acción, para ser punible, debe entrañar un riesgo no permitido, pues toda actividad humana lleva aparejada una probabilidad mayor o menor de accidente ${ }^{42}$. Más aún el deporte, dado que al ser una actividad física, ve aumentado el nivel de riesgo general, especialmente las modalidades violentas o de contacto en las que es muy probable que alguno de los participantes lesione a otro. Desde este enfoque, el Ordenamiento Jurídico aumenta el ámbito de actuación de los sujetos en ciertas actividades consideradas peligrosas, autorizando el (o posible) sacrificio de bienes jurídicos, siempre que no tenga lugar un aumento del riesgo permitido y jurídicamente aceptado. Nuevamente, esta teoría es criticada por parte de la doctrina al no diferir en lo sustancial de la primera ${ }^{43}$. Además, el fundamento de la impunidad se encuentra en el consentimiento explícito o presunto de los deportistas ${ }^{44}$, pues solo puede asumirse lo que se conoce, siendo un consentimiento al riesgo de lesión y no a la lesión en sí, siempre y cuando se observen las reglas del juego, pues "la inimputabilidad de las lesiones depende siempre de que las reglas del juego o lex artis hayan sido respetadas"45, pues la reglamentación es lo comúnmente conocido por todos los participantes. Así, quien practica un deporte conoce que ciertos resultados lesivos pueden tener lugar y, por ello, se trata de un riesgo libremente asumido. Así, el parámetro definido para establecer el límite de riesgo permitido vuelve a ser difuso, concretándose por lo general en la observación de las reglas del juego. De forma que el riesgo permitido es un criterio útil pero no contribuye a determinar qué riesgos son asumidos y cuáles no, del mismo modo que tam-

42 MORILLAS CUEVA, L., "Derecho Penal y deporte...", cit., p. 45. El riesgo permitido no se circunscribe únicamente al deporte, sino que también opera para otros ámbitos de la actividad social, por lo que difícilmente puede justificar una determinada especialidad de aquel. En términos similares, VERDERA SERVER, R., "Una aproximación a los riesgos del deporte", InDret, no. 1, 2003, p. 2.

43 De este modo, FONTÁN TIRADO, R., "Notas a la problemática sobre lesiones deportivas en el Derecho Penal inglés y español...", cit., pp. 274 y 275, considera que existe proximidad entre la teoría de la adecuación social y el riesgo permitido, pues ambas se relacionan entre sí, de forma que la segunda es consecuencia de la primera; DOMÍNGUEZ IZQUIERDO, E.M., "El consentimiento y la relevancia penal de los resultados lesivos en los deportes de contacto eventualmente violentos...", cit., p. 133; y MORILLAS CUEVA, L., Sistema de Derecho Penal. Parte General..., cit., p. 393, expone que el riesgo permitido ha sido identificado con la adecuación social, puesto que la utilidad social típica del sector de la actividad correspondiente impide considerarla relevante típicamente.

44 De este modo, PIÑEIRO SALGUERO considera que debe conectarse la teoría del riesgo con el consentimiento informado. Así, una vez que el sujeto conoce los riesgos y de forma voluntaria practica un determinado deporte, asume los riesgos que del mismo se pueden derivar: "Accidentes deportivos: lesiones consentidas. Análisis de la doctrina de la asunción del riesgo en la responsabilidad civil en el deporte”, InDret, Revista para el Análisis del Derecho, $n^{\circ} .3,2005$, pp. 24 y 25.

45 En este sentido, véanse las SSAP de Castellón de 22 de febrero de 2000, de Zaragoza 54/2012 de 18 de abril, [JUR/2012/178249]; de Cádiz (Sección 7a) 126/2001 de 27 de julio, [ARP/2001/765]; de Zaragoza 325/2009 de 14 de abril, [JUR/2009/219843]; de Baleares 5/2018 de 10 de enero, [JUR/2018/59768]; finalmente, la SAP de Valencia (Sección 11 a) 32/2018 de 14 de febrero, [JUR/2018/92405], pone de manifiesto lo siguiente: en materia de juegos o deportes, la idea del riesgo que cada uno puede implicar va ínsita en los mismos, por tanto, quien los practica, lo asume, siempre y cuando la conducta de los participantes no sobrepase los límites de lo normal. De lo contrario, podría considerarse como una conducta delictiva (ya sea dolosa o culposa). En el deporte, son las reglas de prudencia las que deben seguir los jugadores, debiendo tenerse en cuenta la modalidad deportiva y las circunstancias concurrentes en cada caso, tomando como medida la diligencia del buen deportista, la cual se fundamenta en el compromiso con las reglas del juego y en el respeto a aquellos que con él compiten, incluso si son deportes violentos, sobre el entendimiento de que no se juega para dañar, aunque esto se pueda producir; todos los deportistas conocen desde un principio que la práctica del deporte conlleva la posibilidad de sufrir daños y, como tal, los acepta, siempre que la conducta de los demás respete los límites establecidos; y, se presupone que quien practica un deporte, conoce y acepta los riesgos que del mismo se derivan. 
poco encuentra respaldo legal para hacerlo valedor de prioridad exclusiva como medio de resolución de estas cuestiones ${ }^{46}$. Sin embargo, a pesar de sus carencias, autores como LUZÓN PEÑA plantean que los límites del riesgo en el deporte son claros porque vienen recogidos en las leyes o reglamentos, sobre todo en los deportes violentos ${ }^{47} \mathrm{y}$, de forma similar VERDERA SERVER sostiene que el conocimiento de que la práctica deportiva conlleva unos riesgos, no debe utilizarse como exclusión de cualquier tipo de responsabilidad, ya que solamente encontrarán respaldo en esta tesis los casos que no superan el nivel de riesgo permitido ${ }^{48}$, es decir, los que se ajustan a la normativa deportiva. Por tanto esta teoría vuelve a presentar serias deficiencias pudiendo la asunción del riesgo ser un criterio útil en determinados casos, pero no en todos, para excluir la responsabilidad penal del deportista que lesiona respetando la normativa.

Por las carencias e inconvenientes de las dos perspectivas teóricas anteriores, se ha acudido a la causa de justificación del ejercicio de un oficio o derecho del art. 20.7 CP. Esta eximente constituye una cláusula de cierre del sistema jurídico que impide que la aplicación de las normas que fijan deberes, derechos o funciones sociales pueda verse enfrentada por figuras típicas penales ${ }^{49}$. Al igual que sucedía en los anteriores planteamientos, debe respetarse la reglamentación del deporte para que tenga plena virtualidad ${ }^{50}$ $\mathrm{y}$, en caso de infracción de la normativa deportiva, la justificación (si esto fuera posible) debería buscarse por otros caminos. Esta causa de justificación para la doctrina mayoritaria presenta más ventajas que la adecuación social y el riesgo permitido, dado que no hay que articular una fundamentación extra legem por estar ya contenida en el Código Penal y salva también los problemas de la distinción del deporte profesional y aficionado ${ }^{51}$. En esta línea, el deportista profesional vería amparada su actuación en el ejercicio legítimo de un oficio, mientras que el aficionado, en el del derecho ${ }^{52}$. Por dicha distinción, la justificación prevista en el apartado séptimo del art. 20 CP no despliega eficacia en todo caso, teniendo verdadera relevancia en el profesional ${ }^{53}$. En este sentido, habría que buscarse otras alternativas para el deporte amateur. En tal sentido, MORILLAS FERNÁNDEZ

46 MORILLAS CUEVA, L., "Derecho Penal y deporte...”, cit., p. 45.

47 LUZÓN PEÑA, D.M., Lecciones de Derecho Penal. Parte General, Tirant Lo Blanch, Valencia, 2016, p. 356.

48 VERDERA SERVER, R., “Una aproximación a los riesgos del deporte...”, cit., p. 1.

49 MORILlas CUEVA, L., Sistema de Derecho Penal. Parte General..., cit., pp. 557 y 558. En este caso, deben tenerse en cuenta las exigencias garantizadoras de que el ejercicio de que tales derechos, deberes y funciones socialmente útiles no actúen como una forma de justificar cualquier conducta que en principio parezca jurídicamente amparada y tutelada.

50 DOMÍNGUEZ IZQUIERDO, E.M., "El consentimiento y la relevancia penal de los resultados lesivos en los deportes de contacto eventualmente violentos...", cit., p. 135, establece que "sólo alcanzaría a justificar las lesiones que se ocasionaron en el marco de un juego estrictamente reglamentario".

51 VENTAS SASTRE, R., "Las lesiones en la práctica deportiva: casuística y eventual trascendencia penal", Cuadernos de Política Criminal, n". 91, 2007, p. 76; NAVAS RENEDO, B., "Las reglas de juego como límite a la intervención del Derecho Penal...”, cit., p. 334; LUZÓN PEÑA, D.M., Lecciones de Derecho Penal. Parte General..., cit., p. 443, alega que las causas de justificación extralegales (adecuación social y riesgo permitido) deben encontrar base legal, estando la misma en el art. 20.7 CP; y RÍOS CORBACHO, J.M., Lineamientos de la violencia en el Derecho Penal del deporte..., cit., p. 259. Esta perspectiva teórica, a pesar de ser seguida por un amplio sector doctrinal, no está exenta de críticas. Así, DOMÍNGUEZ IZQUIERDO, E.M., "El consentimiento y la relevancia penal de los resultados lesivos en los deportes de contacto eventualmente violentos...", cit., p. 137, plantea que es muy similar a la adecuación social si se completa con el principio de insignificancia, en los casos de lesiones muy leves por escaso desvalor de la acción y tampoco se aleja del riesgo permitido.

52 De esta opinión, MORILLAS CUEVA, L., Sistema de Derecho Penal. Parte General..., cit., p. 580, quien alega que el legislador lo configura unitariamente pero su contenido y fuentes de legitimación difieren.

53 En este sentido, véase, $i b d$., p. 592. 
aboga por un planteamiento ecléctico que combina la teoría del riesgo permitido y el ejercicio de la profesión. El primero operaría para el deporte aficionado, mientras que el segundo para el profesional ${ }^{54}$. A nuestro entender, este posicionamiento sería el más adecuado, puesto que no existe un derecho a la práctica deportiva en tanto la CE solo hace alusión expresa al deporte por el mandato de fomento al legislador contenido en el art. 43.3, del mismo modo que no se tiene derecho a lesionar a otra persona y la práctica deportiva no implica ejecutarla sin tener en cuenta la normativa ${ }^{55}$. Por tanto, el criterio del riesgo permitido sería la vía adecuada para el deporte aficionado porque quien decide voluntariamente practicar una determinada actividad, asume los riesgos habituales de la misma, eso sí, siempre y cuando el contrincante haya actuado conforme a lo establecido reglamentariamente, mientras que la causa de justificación del art. 20.7 CP únicamente ampararía las lesiones derivadas de la práctica profesional, teniendo en cuenta como en el caso anterior, el respeto a las reglas del juego.

Como todas las teorías mencionadas tienen su base en el respeto a las reglas del juego, consideramos que para las lesiones derivadas de una acción ejecutada con obediencia de la normativa no habría que buscarse otros parámetros de licitud distintos, siendo el actuar reglamentario criterio suficiente para considerar impune al deportista que lesiona con estricta observancia de los límites normativos, por lo que únicamente cabría aplicar una sanción proveniente del ámbito disciplinario deportivo. Cuestión distinta son aquellas acciones ejecutadas quebrantando la normativa, pues en dicho caso ya no opera el fundamento de observancia de las reglas del juego sino que, en función de la entidad del resultado, habría que buscarse otros argumentos teóricos.

\subsubsection{Infracción de las reglas que no causa lesión}

Este supuesto ${ }^{56}$ empieza a plantear más problemas que el anterior dado que, como acabamos de señalar, el respeto a las reglas del juego es el requisito fundamental para determinar la impunidad de una conducta antideportiva independientemente del resultado por lo que, a priori, entraría dentro de lo punible desde el momento en que supone una transgresión de aquellas. Sin embargo, se considera suficiente el recurso a la sanción deportiva, de aplicación a parte de las conductas temerarias e imprudentes y aquellas ejecutadas con fuerza excesiva, siempre y cuando no se produzca lesión ${ }^{57}$, pues en caso contrario ya se estaría en supuestos de dolo o imprudencia. Bajo nuestro punto de vista, no todas las acciones encuadrables en esta hipótesis son acreedoras únicamente de sanción deportiva, dado que las cometidas intencionadamente fuera de un lance del juego, podrían merecer el oportuno reproche penal. De forma similar se pronuncia ESER, para quien el ataque corporal si tiene lugar en un lance del juego y no conlleva resultado lesi-

54 MORILLAS FERNÁNDEZ, D.L., “La justificación de las lesiones deportivas...”, cit., p. 116.

55 De esta opinión, MONROY ANTÓN, A.J.: "El delito de lesiones en el deporte: evolución y diferencias entre la legislación alemana y la española. Propuesta de solución”, en el X Congreso de Historia del Deporte, Sevilla, 2005, p. 9.

56 Este tipo de incidentes son los denominados ilícitos deportivos, entendiendo como tal todo aquel "comportamiento que, infringiendo las reglas que rigen el correcto desarrollo de una disciplina deportiva, no merecen persecución penal en tanto no resultan perjudiciales para la integridad física de la persona por no superar los límites del riesgo permitido": MORILLAS FERNÁNDEZ, D.L., "La justificación de las lesiones deportivas...,", cit., p. 115.

57 BENÍTEZ ORTÚZAR, I.F., "Imprudencia en la práctica del deporte e imprudencia jurídico-penal. Necesidad de delimitar un ámbito específico del Derecho disciplinario deportivo", en Morillas Cueva, L., y Mantovani, F., (Dirs.) y Benítez Ortúzar, I.F., (Coord.), Estudios sobre Derecho y deporte, Dykinson, Madrid, 2008, p. 61. 
vo, no sobrepasa el umbral del tipo de lesiones, por lo que se declara su impunidad; no así aquellas acciones ejecutadas fuera del normal desarrollo de la competición con intención manifiesta puesto que ya entrarían dentro del ámbito de los malos tratos típicos y antijurídicos pudiéndose únicamente atenuar la responsabilidad por la fuerza de la emoción ${ }^{58}$ que supone toda práctica deportiva, especialmente las de contacto. En tal sentido, no todas las acciones ejecutadas trasgrediendo la normativa deportiva sin resultado lesivo deben ser impunes, puesto que ciertos ataques a los bienes jurídicos son de tal entidad que darían lugar a la intervención punitiva en aplicación de lo dispuesto en el art. 147.3 CP del maltrato de obra sin lesión, pues tal como asevera PAREDES CASTAÑÓN, las infracciones de las reglas del juego que amenazan (y lesionan) bienes jurídicos deben ser sancionadas por el Derecho Penal ${ }^{59}$; pero no todas, solo aquellas que tengan lugar durante un lance del juego, no excedan los límites establecidos en la normativa deportiva y no supongan una amenaza seria a la salud del deportista.

Algunos incidentes que podrían ser merecedores de pena a través de lo establecido en el apartado tercero del art. 147 CP serían (entre otros muchos) el escandaloso cabezazo que Zidane propinó en el pecho a Materazzi en la final del Mundial de fútbol de Alemania del año 2006, al tener lugar en un momento en el que no se estaba disputando el esférico, por lo que muy difícilmente puede admitirse que se trataba de un lance del juego ${ }^{60}$, además de constituir una agresión desproporcionada con fuerza excesiva; igualmente, la brutal patada que recibió Xabi Alonso en el pecho por parte de De Jong durante la final del Mundial de Sudáfrica del año 2010 pues una patada en esa zona del cuerpo con la energía con la que fue propinada supone una grave amenaza a la salud ${ }^{61}$. De semejante opinión RÍOS CORBACHO, para quien este tipo de casos no pueden ampararse en ninguna de las teorías articuladas por la doctrina para considerar su atipicidad ${ }^{62}$. No obstante, tales incidentes suscitan controversias a la hora de aplicar lo dispuesto en el Derecho Penal para el tipo de maltrato de obra por varios motivos. Por un lado, la habitualidad con la que tienen lugar, dado que son muy frecuentes y por ese motivo, los contendientes los consideran normales; y, por otro, estrechamente relacionado con el anterior, se estarían criminalizando un buen número de conductas que tienen lugar asiduamente durante una competición por lo que, de lege lata, suele aplicarse solamente la disciplina deportiva ${ }^{63}$.

58 El autor alemán ejemplifica la responsabilidad penal por malos tratos a través del fútbol con el hipotético caso de un delantero fracasado que, tras realizar una actuación sin éxito, logra derribar al defensa con un gancho en la mandíbula. ESER, A., "Lesiones deportivas y Derecho Penal...", cit., p. 4.

59 PAREDES CASTAÑÓN, J.M., "Consentimiento y riesgo en las actividades deportivas...”, cit., p. 656.

60 De esta opinión, RÍOS CORBACHO, J.M., Lineamientos de la violencia en el Derecho Penal del deporte..., cit., p. 275. En el momento en el que tuvieron lugar los hechos, la conducta del astro galo podría catalogarse dentro de la derogada falta prevista en el anterior art. 617.2 CP.

61 Más recientemente, en el encuentro entre España y Suecia del pasado 14 de noviembre de 2021 para la clasificación del Mundial de Fútbol de 2022 que se celebrará en Qatar, Ibrahimovic en el minuto 92 cuando se iba a llevar a cabo un saque de esquina a favor de Suecia a sazón, perdedora en ese momento por 1-0, arremetió fuertemente con el hombro a Azpilicueta con clara intención, a resultas de lo cual, este último chocó con otro compañero al no esperar el golpe. Por tal acción, Zlatan solamente recibió una amonestación. Sin embargo, a nuestro juicio, sería merecedor no solo de sanción deportiva, sino también de una penal.

62 RÍOS CORBACHO, J.M., "Palabra de fútbol” y Derecho Penal, Reus, Madrid, 2015, p. 49.

63 DE VICENTE MARTÍNEZ, R., Derecho Penal del deporte..., cit., pp. 150 y 151. De manera residual llega algún incidente de este tipo a instancias judiciales y los pocos que llegan se desestiman. De este tenor, la SAP de Barcelona 415/2004 de 21 de junio, [JUR/2004/203656] en la que se enjuicia un suceso acaecido durante un partido de hockey en el que el demandado golpeó un ojo al actor al alzar con el stick. La pretensión del actor fue rechazada por considerar el Juez que no había delito. No obstante, existe algún pronunciamiento judicial en el que 


\subsubsection{Lesiones ocasionadas con imprudencia}

Los resultados lesivos que se derivan de una acción imprudente son los que mayores problemas presentan en lo relativo a la determinación de la punibilidad de la conducta. La imprudencia se determina por la magnitud de la infracción del deber de cuidado o diligencia del autor, lo cual se vincula con el nivel de riesgo no permitido derivado de la conducta del sujeto. En el deporte, la imprudencia tiene lugar en el momento en que el atleta actúa dentro de lo aceptado en la concreta modalidad deportiva como lo haría el deportista medio, aunque con infracción del reglamento, no mereciendo en un primer momento sanción penal ${ }^{64}$. La tendencia doctrinal mayoritaria en este caso se dirige hacia la impunidad ${ }^{65}$. Sin embargo, no todas las lesiones imprudentes en el ámbito deportivo tienen la misma intensidad por lo que no merecen idéntica respuesta. En esta línea, los supuestos que derivan en resultado lesivo como consecuencia de un actuar levemente imprudente por parte del agente, entran dentro de la normalidad del juego y suelen derivar del ímpetu de los jugadores a los que se les exige un menor nivel de diligencia del habitual ${ }^{66}$, por lo que quedan extramuros del ámbito penal al ser atípicos ${ }^{67}$, dirimiéndose en exclusividad en el ámbito federativo en base al principio de intervención mínima y carácter de ultima ratio del Derecho Penal, pues lo contrario haría inservible el reglamento deportivo derivando de ello además una excesiva criminalización del deporte, debiendo intervenir únicamente en los casos de mayor gravedad ${ }^{68}$. Así, en un primer momento puede revestir caracteres delictivos la entrada por detrás que realiza un futbolista que tiene intención de cortar una ocasión manifiesta de gol y, no teniendo a su alcance otros medios menos dañosos, realiza dicha acción de la cual se deriva un resultado lesivo y, sin tener ánimo de lesionar conoce que de su actuar imprudente puede derivarse el resultado que

se ha condenado por la antigua falta del art. 617.2 CP, como la SAP de Las Palmas (Sección 2a) 151/2014 de 15 de septiembre, [JUR 2015/45849] en la que se califica como maltrato de obra sin lesión la acción de agarrar por la camiseta a un contrario durante un partido de pádel, alegándose que supone una actuación agresiva que no llega a provocar lesión pero integra el concepto del maltrato de obra.

64 MORILlAS CUEVA, L., "Derecho Penal y deporte...", cit., pp. 47 y 48. Para el autor, la imprudencia en el deporte tiene lugar cuando la lesión deriva de la infracción de los deberes de cuidado impuestos normativamente en una determinada situación a los individuos medios, "razonables y concienzudos" que pertenecen al círculo del autor o, lo que es lo mismo, los demás deportistas de esa modalidad y el resultado es previsible para una persona de ese nivel.

65 Para lo cual se han esgrimido muchos argumentos. De todas, las teorías más extendidas son las del consentimiento, la adecuación social, el riesgo permitido y el ejercicio legítimo de un derecho, oficio o cargo del art. 20.7 CP: RÍOS CORBACHO, Lineamientos de la violencia en el Derecho Penal del deporte..., cit., p. 250.

66 PIÑEIRO SALGUERO, J., “Accidentes deportivos: lesiones consentidas...", cit., pp. 34-37. Continúa alegando que los problemas se presentan en los supuestos intermedios que dañan sin constituir negligencia grave o dolo. Es esencial determinar qué se entiende por lance normal del juego que el deportista debe asumir y a partir de dónde se aprecia negligencia suficiente para considerarle responsable. El autor establece unos parámetros a partir de los cuales la conducta del individuo sería reprochable: a) el acto debe ser durante y a consecuencia del deporte; b) observación del cumplimiento de la reglamentación deportiva; c) en caso de infringirse la normativa, debe apreciarse si el comportamiento es normal o habitual en la modalidad deportiva de que se trate; y d) gravedad de la lesión. En caso de no darse alguno de esos requisitos, no habría problema en considerar punible la conducta del agente.

67 En este sentido, BENÍTEZ ORTÚZAR sostiene que la atipicidad deriva de la levedad de la infracción reglamentaria, lo cual permite imputar el resultado lesivo al aumento del riego generado por el individuo lesionado y la teoría de la autopuesta en peligro: "Derecho Penal y deporte en España...", cit., p. 60. De forma similar, DOMÍNGUEZ IZQUIERDO sostiene que hay un interés general en aceptar la infracción porque estas situaciones son imprescindibles para el correcto desarrollo del encuentro o competición, del mismo modo que se admiten otros comportamientos que conllevan riesgo realizados con una finalidad legítima: "El consentimiento y la relevancia penal de los resultados lesivos en los deportes de contacto eventualmente violentos...", cit., p. 163.

68 RÍOS CORBACHO, J.M., Lineamientos de la violencia en el Derecho Penal del deporte..., cit., p. 264. 
finalmente tiene lugar y, aun así no desiste en su empeño. Sin embargo, tal actuación no entra dentro de lo punible ${ }^{69}$. En este sentido, la mayoría de incidentes constitutivos de imprudencia leve no llegan a conocimiento de los Tribunales y los que lo hacen, suelen obtener pronunciamientos absolutorios ${ }^{70}$. Por tanto, para resarcir la responsabilidad del individuo en casos levemente imprudentes, basta con la aplicación de la disciplina deportiva, al suponer una infracción nimia de las reglas, carecer de intencionalidad de lesionar y producirse durante una jugada habitual del deporte de que se trate, por lo que no superan el umbral del riesgo permitido para considerarse penalmente relevantes.

Cuestión bien distinta son los casos de imprudencia grave que constituyen una violación de las normas más elementales de diligencia debida y el desprecio más absoluto del deber de cuidado, sobrepasando en demasía la normativa deportiva ${ }^{71}$. Por este motivo, el Derecho Penal debe conocer de este tipo de lesiones pues de lo contrario, no cumpliría su función de protección de bienes jurídicos ${ }^{72}$. Lo lógico, por tanto, sería que fuesen sancionados penalmente, debiendo hacerse un juicio de valoración sobre la previsibilidad del resultado y si el lesionado podía haberlo evitado de haber actuado de forma distinta ${ }^{73}$, a lo que se añade la ausencia de intención del individuo agresor y la causación efectiva de la lesión que debe precisar tratamiento sanitario para su curación, tal como queda acreditado en la SAP de Zaragoza 325/2009 de 14 de abril, [JUR/2009/219843]. A pesar de ello, al igual que sucedía en el caso anterior, los tribunales no suelen condenar por tales incidentes, sosteniendo su impunidad, aunque dicha tendencia está comenzando a revertirse y ya existe algún pronunciamiento en este sentido ${ }^{74}$. Sin embargo, se han articulado una serie de teorías tendentes a justificar este tipo de situaciones.

69 Por el contrario, si el sujeto tiene a su alcance otras posibilidades para evitar el avance del contrincante (como sujetar) que minimicen los daños pero no las tiene en cuenta y realiza la entrada peligrosa, podría considerarse delito imprudente, siempre y cuando exista infracción de la norma de cuidado, la previsibilidad objetiva del resultado y su efectiva producción. El autor señala además que para deportes como el boxeo no tendría virtualidad porque el fin último de esta práctica es lesionar al oponente. De esta opinión ibd., pp. 263 y 264.

70 Entre otras, véase la SAP de Madrid (Sección 33) 438/2004 de 19 de noviembre, [JUR 2005/256706], en la que se absuelve al profesor acusado de la falta de lesiones por imprudencia leve del ya derogado art. $621.3 \mathrm{CP}$ de la que se le venía acusando por las lesiones y secuelas ocasionadas a un alumno menor de edad. El incidente tuvo lugar por una entrada sin querer de aquel que golpea a este último causándole lesión. La citada sentencia expone que cuando se violan imprudentemente las reglas del juego con resultado lesivo, no se acude al Derecho Penal por ser supuestos impunes, social y consuetudinariamente aceptados, siendo normal esperar algún exceso involuntario por parte de los participantes. De las diligencias se deduce que el imputado jugaba al fútbol como tantas otras veces cuando en una jugada el denunciante llevaba el balón y tuvo lugar un golpe involuntario, a resultas del cual derivaron las lesiones. Además, de la prueba no se desprende que el denunciado actuase con temeridad y desprecio a las más elementales normas de cuidado, razón por la que finalmente queda absuelto de la falta por la que se le venía acusando; y la SAP de La Rioja 43/2002 de 8 de marzo, [JUR 2002/138424]. La excepción de la exclusión de responsabilidad por imprudencia leve se encuentra en la SAP de Zaragoza (Sección 3a) 14/2006 de 12 de enero, [JUR 2006/83445].

71 BENÍTEZ ORTÚZAR, I.F., “Imprudencia en la práctica del deporte e imprudencia jurídico-penal...”, cit., pp. 75-77.

72 De esta opinión, MORILlAS CUEVA, L., "Derecho Penal y deporte...”, cit., p. 49.

73 VENTAS SASTRE, R., "La tutela penal...", cit., p. 580. De forma parecida se pronuncian DE VICENTE MARTÍNEZ, R., Derecho Penal del deporte..., cit., p. 153, para quien el Derecho Penal debe intervenir cuando quede acreditada la relevancia material de la conducta con respecto a la vida o salud física de los deportistas; y ANDERSON, J., "Citius, Altius, Fortius? A study of Criminal Violence in Sport”, Marquette Sports Law Review, vol. 11, no. 11, 2000, pp. 95 y 96. Este último sostiene que si el sujeto sabe que podría causar daño aunque no lo quiera, sería culpable de un hecho criminal, el comportamiento en ese caso es ilegal porque "nadie tiene derecho a usar la fuerza para herir a otro".

74 Véase, la SAP de Madrid (Sección 23 $3^{a}$ ) 442/2011 de 29 de octubre, [JUR/2012/65445] que trae causa de un recurso interpuesto a la Sentencia del Juzgado de Instrucción núm. 19 de Madrid, que previamente había condenado por falta de lesiones graves del art. $621.1 \mathrm{CP}$ al profesor de boxeo que en la segunda clase del alumno, con falta 
La primera de ellas, relativa al consentimiento ${ }^{75}$, plantea que éste puede eximir de responsabilidad cuando el sujeto pasivo conoce el riesgo que comporta la conducta y, a pesar de ello, se expone a la situación de peligro ${ }^{76}$. De modo que quien acepta participar en un deporte conoce los riesgos que conlleva, actúa como propio riesgo y consiente en las lesiones que de su práctica puedan derivarse. Empero, esto no viene a significar que se consientan las propias lesiones, puesto que en un primer momento no se debería sufrir ningún ataque a la salud, por lo que únicamente este argumento sería válido en los deportes violentos ${ }^{77}$ como el boxeo, o en los de contacto físico como el fútbol. En este sentido, se plantea qué es lo que el deportista consiente, pues no consentirá la lesión en sí, sino en el riesgo de que la misma tenga lugar, es decir, la conducta descuidada que pone en peligro los bienes objeto de protección penal indicados, sin que esto suponga la aceptación del resultado ${ }^{78}$. La jurisprudencia se ha pronunciado ya sobre esta cuestión en la SAP de Zaragoza 325/2009 de 14 de abril, [JUR/2009/219843], en la que se expone que el consentimiento tanto en el deporte profesional como en el amateur, no es un consentimiento a ser lesionado, sino en el riesgo de lesión, es decir, que como consecuencia de un lance del juego donde existe con-

de pericia y cuidado por no contar este último con los conocimientos necesarios, le propinó varios golpes que derivaron en lesiones que requirieron tratamiento quirúrgico para su sanidad. En el recurso se alega que no existió intención en el agente, fueron fortuitas y propias del riesgo de un deporte como el boxeo, pero finalmente se desestima. La Sala entiende que, aunque las lesiones fueron causa de la práctica del boxeo, debe tenerse en cuenta que el denunciante no era deportista profesional ni siquiera amateur, sino que acudía a un gimnasio a entrenar y recibir clases de boxeo. Además, por ser su segunda sesión, se presume la ausencia de conocimiento sobre dicha actividad. A ello debe añadirse que el causante de las lesiones es un profesor al que se le supone una pericia y conocimientos relativos a ese deporte suficientes como para, según la aptitud del alumno, tener la debida diligencia para no causarle daño alguno; tampoco se adoptaron las medidas de precaución ni se pusieron los medios idóneos para impedir las lesiones y, finalmente, el entrenamiento debía haberse ajustado a los conocimientos del alumno, por lo que no debe ponerse en riesgo su integridad, obligándole a hacer ejercicios para los que no estaba preparado. Del golpe, se derivaron graves lesiones dejándole además en shock. Por este motivo, tuvo que estar hospitalizado y ser intervenido. Así, se puede concluir que las lesiones tuvieron lugar fuera de los límites normales del boxeo que, aun de contacto, debe ejecutarse en condiciones tales que garanticen la seguridad e integridad de los participantes. En el proceso de aprendizaje, el profesor se encuentra en una situación de superioridad con respecto a sus alumnos, estando de este modo afectado por los específicos deberes de su oficio. En tales casos, la asunción del riesgo por los alumnos no absorbe la creación de riesgo por el profesor, al que se le exige un plus de diligencia. Así, la asunción del riesgo sólo es operativa si la actuación ha sido irreprochable, lo cual aquí no acontece. La doctrina también se posiciona en tales términos. Entre otros, MEDINA ALCOZ, M., La asunción del riesgo por parte de la víctima. Riesgos taurinos y deportivos, Dykinson, Madrid, 2004, p. 293; y DE VICENTE MARTÍNEZ, Derecho Penal del deporte..., cit., p. 153.

75 El consentimiento constituye el acto de disposición del bien jurídico por su titular quien renuncia a su protección y, a consecuencia de ello, el Estado no tiene interés en la persecución penal de la conducta. MORILLAS CUEVA, L., “Consentimiento y consentimiento presunto, ¿Dos formas de un mismo todo?”, en Álvarez García, J., y otros (Coords.), Libro Homenaje al profesor Luis Rodríguez Ramos, Tirant lo Blanch, Valencia, 2013, p. 144.

76 PORTILLA CONTRERAS, G., "Tratamiento dogmático-penal de los supuestos de puesta en peligro imprudente por un tercero con aceptación por la víctima de la situación de riesgo", Cuadernos de Política Criminal, $\mathrm{n}^{\circ}$. 45, 1991p. 713. En caso contrario, es decir, cuando se acepte o confíe que la lesión no va a producirse, la eficacia del consentimiento es dudosa.

77 ESER, A., "Deporte y justicia penal”, Revista Penal, nº 6, 2000, p. 54; de forma parecida, QUERALT JIMÉNEZ, J.J., Derecho Penal Español. Parte Especial, Tirant Lo Blanch, Valencia, 2015, pp. 93 y 95; SUÁREZ LÓPEZ, J.M., y MORILLAS FERNÁNDEZ, D.L., "Derecho Penal y deporte. Planteamiento general. Las lesiones deportivas. El tratamiento penal del dopaje”, en Palomar Olmeda, A., (Dir.) y Rodríguez García, J., (Coord.), Derecho del deporte, $2^{\text {a }}$ Ed., Thomson-Reuters Aranzadi, 2017, p. 626; y MUÑOZ CONDE, Derecho Penal. Parte Especial, Tirant lo Blanch, Valencia, 2019, p. 119.

78 BERDUGO GÓMEZ DE LA TORRE, I., "El consentimiento en las lesiones...”, cit., p. 215. El autor indica que, frente a esta postura, otros esquemas llevan necesariamente a exigir que el consentimiento abarque el resultado, con lo cual se estrecha el ámbito de incidencia del consentimiento del lesionado en los delitos imprudentes; y MIR PUIG, S., Derecho Penal. Parte General, Reppertor, Barcelona, 2016, p. 528. 
tacto con otro competidor, se pueda sufrir una lesión ${ }^{79}$. Esto se debe al hecho de que, quien participa en deportes violentos, presta su anuencia al riesgo que dichas actividades comportan pero no por ello legitima que se le lesione. Cuando un individuo decide participar en un deporte, lo hace con la confianza de que los demás jugadores van a respetar las reglas y se empeñan en ello, aunque también está dispuesto a aceptar ciertas infracciones, pero lo que nunca aceptará es el resultado lesivo derivado de una acción gravemente imprudente ejecutada sin la observación del más mínimo respeto a las mismas. Otra cuestión problemática que pivota en torno al consentimiento es la disponibilidad de los bienes jurídicos, pues tanto la vida como la salud son indisponibles. Especialmente este último, ya que solamente es disponible para la autolesión, operando la indisponibilidad frente terceros que, aunque actuaran con la aquiescencia del sujeto pasivo, estarían realizando una conducta típica puesto que el menoscabo al bien jurídico persiste ${ }^{80}$, motivo por el que el consentimiento no opera como eximente sino como atenuante (art. $155 \mathrm{CP}$ ). Por todo lo indicado, entendemos que el argumento del consentimiento no puede ser utilizado para eximir de responsabilidad penal al individuo agresor, pudiendo en todo caso, atenuar la responsabilidad pero nunca excluirla. Más aún cuando la lesión se produce con inobservancia grave de las reglas del mínimo cuidado exigido y tolerado por el sujeto pasivo.

Dadas las dificultades que el anterior plantea, se ha acudido al argumento de la adecuación social, por el que las actividades peligrosas como el deporte, por su utilidad social, son consideradas lícitas, determinándose así la impunidad de los hechos que en su seno acontecen, puesto que de ocurrir en otro contexto serían a todas luces, punibles ${ }^{81}$. En el deporte, la adecuación social tiene cabida cuando el deportista actúa dentro de los límites permitidos. De esta forma, siguiendo a RÍOS CORBACHO, se puede afirmar que la actitud del defensa que intenta interceptar a un delantero para que no consiga llegar a la portería contraria, estaría dentro de la adecuación social, al suponer meramente una falta deportiva ${ }^{82}$; o, el jugador de rugby que en un placaje pierde varias piezas dentales,

79 En el pronunciamiento se pone como ejemplo el caso del futbolista que no se presta voluntariamente a que le partan una pierna durante un partido, ni el jugador de rugby a lesiones craneales como resultado de un placaje. Así, en el fútbol, pueden condenarse penalmente como imprudentes, las acciones de un jugador que sin posibilidad de disputar el balón ataque violentamente al rival sin intención de lesionarlo pero con previsibilidad de ello, siendo necesario además que la lesión haya tenido lugar y que precise tratamiento. Siguiendo este pronunciamiento, la SAP de Baleares 5/2018 de 10 de enero, [JUR/2018/59768], si bien ésta termina condenando por delito de lesiones por quedar acreditada la intencionalidad del agente.

80 En esta línea se manifiesta buena parte de la doctrina, entre otros, GONZÁLEZ RUS, J.J., "Lección 4. Las lesiones", en Cobo del Rosal, M., (Coord.), Derecho Penal español. Parte Especial, Dykinson, Madrid, 2005, p. 144; LUZÓN PEÑA, D.M., Lecciones de Derecho Penal. Parte General..., cit., pp. 321 y 322; y DEL ROSAL BLASCO, B., "Capítulo 4. Las lesiones", en Morillas Cueva, L., (Dir.), Sistema de Derecho Penal. Parte Especial, Dykinson, Madrid, 2020, pp. 102 y 103. En sentido contrario se muestran otros autores. Tal es el caso de BERDUGO GÓMEZ DE LA TORRE, I., "El consentimiento en las lesiones", Cuadernos de Política Criminal, $\mathrm{n}^{\circ} .14,1981$, pp. 210 y 211. Para el mismo, la salud es disponible porque en el delito de lesiones, el bien jurídico tutelado está formado por la capacidad de disponer de la salud y de su sustrato material.

81 MIR PUIG, S., Derecho Penal. Parte General..., cit., pp. 534 y 535. Se suelen admitir este tipo de actividades porque, siendo útiles para la sociedad, no son directamente lesivas, sino solo peligrosas. A veces se admiten conductas que implican por sí mismas lesiones, como ocurre con el boxeo, actividad en la que los púgiles tienen la intención de causarse lesiones, pues es la base de este deporte. En este sentido, una actividad peligrosa socialmente adecuada no deja de estar permitida porque los sujetos la realicen con el deseo de que se produzca la lesión. Tal como afirma LUZÓN PEÑA, las conductas consideradas como socialmente adecuadas, inicialmente encajan en el tipo pero por su carácter normal, derivan en causa de atipicidad: Lecciones de Derecho Penal. Parte General..., cit., pp. 322 y 323.

82 RÍOS CORBACHO, J.M., Lineamientos de la violencia en el Derecho Penal del deporte..., cit., p. 257. 
pues son circunstancias que entran dentro de lo previsible en la dinámica de la concreta actividad. Pero como señalamos anteriormente, consideramos que no toda conducta imprudente con resultado lesivo en el deporte debe conocerse únicamente por la disciplina deportiva; si bien algunos autores, en sentido distinto, se muestran partidarios de usar el criterio de la adecuación social para todos los tipos imprudentes, tanto graves como leves. En tal línea VALLS PRIETO argumenta que las lesiones deportivas imprudentes, independientemente de su intensidad, no deberían sancionarse, ya que la representación que se hace el sujeto activo del riesgo, por el contexto deportivo en el que se produce, es aceptado por la sociedad ${ }^{83}$. Aun así, entendemos más acertado el posicionamiento de buena parte de la doctrina, en tanto considera que el argumento de la adecuación social no se puede esgrimir en este caso. Así, con buen criterio, MONROY ANTÓN alega su vaguedad, puesto que no queda claro qué es lo considerado socialmente adecuado, añadiendo además que solamente acogería las conductas reglamentarias, siendo punibles todas las demás ${ }^{84}$. Igualmente, RODRÍGUEZ-MOURULLO y CLEMENTE apuntan la dificultad de justificar una supuesta especialidad del deporte respecto de otros ámbitos de la sociedad ${ }^{85}$. En vista de las carencias que presenta, entendemos que la adecuación social no constituye un parámetro válido para los casos de imprudencia grave, puesto que solo operaría para aquellos en los que se ha respetado la normativa y tal circunstancia no tiene lugar en las lesiones deportivas de este tipo.

En un intento por articular una respuesta adecuada, surgió el planteamiento del riesgo permitido, siendo éste el que mayor cobertura justificativa otorga a los supuestos de imprudencia y tiene como base el consentimiento del titular ${ }^{86}$, especialmente en los deportes de contacto recíproco directo como el fútbol ${ }^{87}$. Bajo este planteamiento, la lesión derivada del actuar gravemente imprudente del sujeto es previsible y querida en este tipo de deportes, asumiéndose el riesgo de que la misma se produzca ${ }^{88}$, por lo que sería impune.

83 VALLS PRIETO, J., “La intervención del Derecho Penal en la actividad deportiva...”, cit., p. 7. De forma parecida, FLORA plantea que deberían considerarse penalmente irrelevantes las lesiones deportivas, incluso aquellas que violan las reglas del juego, atendiendo a las consecuencias objetivamente previsibles e implícitamente aceptadas por el deportista, en tanto derivan de una conducta proporcional al nivel de compromiso agonístico inherente al tipo de competición; pues constituye un fenómeno de defecto de tipicidad, una acción socialmente adecuada, lo cual supone el límite de la tipicidad: "Diseño de una tutela penal de la salud en la actividad deportiva", en Morillas Cueva, L., y Mantovani, F., (Dirs.) y Benítez Ortúzar, I.F., (Coord.), Estudios sobre Derecho y deporte, Dykinson, Madrid, 2008, p. 218.

84 MONROY ANTÓN, A.J., "Las lesiones deportivas desde una doble perspectiva jurídica-histórica...", cit., p. 1. EL MISMO en "El delito de lesiones en el deporte...", cit., p. 3. En idénticos términos, DOMÍNGUEZ IZQUIERDO, E.M., "El consentimiento y la relevancia penal de los resultados lesivos en los deportes de contacto eventualmente violentos...", cit., p. 132.

85 RODRÍGUEZ-MOURULlO, A., y CLEMENTE, I., “Dos aspectos de Derecho Penal en el deporte...”, cit., p. 13.

86 RÍOS CORBACHO, J.M., Lineamientos de la violencia en el Derecho Penal del deporte..., cit., pp. 250-253. E1 autor declara que el consentimiento hay que probarlo en el caso concreto, ya que lo contrario sería una conducta antijurídica.

87 DOMÍNGUEZ IZQUIERDO, E.M., "El consentimiento y la relevancia penal de los resultados lesivos en los deportes de contacto eventualmente violentos...", cit., p. 138.

88 En este sentido, PAREDES CASTAÑÓN, J.M., "La responsabilidad penal del deportista...", cit., pp. 85 y ss. Un ejemplo de esto sería el caso 6 de la larga lista que desarrolla el autor en este trabajo. A golpea a B con intención de fracturarle la nariz, lo cual efectivamente sucede pero es atípica por el riesgo permitido, dado que el boxeador lesionado conoce que estos resultados pueden tener lugar y aun así decide participar. Esta es una conducta gravemente peligrosa ex ante para el bien jurídico salud. Se apuesta por el riesgo permitido en este caso, dado que la ponderación de los intereses en juego lleva a la conclusión de que merece la pena sacrificar alguna protección del bien jurídico. 
Sin embargo, hemos de señalar que no toda lesión es previsible y querida, sino únicamente aquella que se encuadre dentro de las acciones normales del juego. Así, no tiene cabida en el riesgo permitido en el deporte del boxeo, la acción del individuo que da un rodillazo en la zona testicular al contrincante, derivando de la misma lesiones que culminan en la extirpación del testículo derecho, como queda puesto de manifiesto en la STS (Sala de lo Penal, Sección 1a) 360/2013 de 1 de abril, [RJ 2013/7272]. Así las cosas, lo que plantea esta teoría es la impunidad de las acciones lesivas en base al conocimiento del riesgo de que tengan lugar pero bajo la esperanza de que finalmente no se produzcan ${ }^{89}$. Una cuestión que plantea dificultades en este planteamiento es la de distinguir el riesgo permitido del que no lo es, encontrándose normalmente en los reglamentos que limitan el ejercicio de la violencia o lex $\operatorname{artis}^{90}$. En base a tal delimitación, las acciones gravemente imprudentes ocasionadas en el deporte constituyen un riesgo excesivo por sobrepasar lo establecido en la normativa deportiva, motivo por el que entendemos que deben ser punibles en todo caso ${ }^{91}$. De tal forma que, siguiendo a ESER, podemos afirmar que el límite de la permisividad está en el riesgo no tolerado, en las infracciones graves que conllevan un riesgo aumentado y manifiesto de lesión, pudiendo deducirse el nivel del riesgo de la alta probabilidad de que la misma tenga lugar y de la gravedad potencial del supuesto. Es por ello que las lesiones causadas por imprudencia grave no pueden incluirse en el riesgo permitido ${ }^{92}$.

Finalmente, la doctrina mayoritaria ha acudido a la causa de justificación prevista en el art. 20.7 CP como argumento legitimador de los casos ejecutados mediando grave imprudencia ${ }^{93}$. Nuevamente, para que la misma tenga virtualidad, el individuo debe haber observado objetivamente el cuidado debido en la práctica deportiva, de lo contrario, el ejercicio del derecho o profesión serían ilegítimos. Por tanto, para que las lesiones deportivas puedan justificarse por vía del art. 20.7 CP es necesario que la actuación lesiva se ajuste a la reglamentación ${ }^{94}$. Esta causa de justificación no es unánimemente aceptada, siendo criticada por algún sector doctrinal, pues aunque el deporte fuese considerado un derecho de la ciudadanía (cuestión que no acontece), no puede constituir la causa que exima de responsabilidad en los casos de imprudencia grave, ya que se estaría legitimando cualquier tipo de lesión y no existe un supuesto derecho a lesionar a otro, por lo que únicamente incluiría las lesiones provenientes de actuaciones reglamentarias ${ }^{95}$, puesto que constituiría una extralimitación del derecho a practicar una actividad deportiva, ya sea en

89 BERDUGO GÓMEZ DE LA TORRE, I., "El consentimiento en las lesiones...”, cit., p. 217.

90 Cfr. RODRÍGUEZ-MOURULlO, A., y CLEMENTE, I., "Dos aspectos de Derecho Penal en el deporte...,", cit., pp. 16 y 17.

91 DOMÍNGUEZ IZQUIERDO, E.M., "El consentimiento y la relevancia penal de los resultados lesivos en los deportes de contacto eventualmente violentos...", cit., pp. 133 y 134; y RODRÍGUEZ-MOURULLO, A., y CLEMENTE, I., "Dos aspectos de Derecho Penal en el deporte...", cit., pp. 16 y 17.

92 ESER, A., "Lesiones deportivas y Derecho Penal...", cit., p. 5; igualmente, FONTÁN TIRADO, R., "Notas a la problemática sobre lesiones deportivas en el Derecho Penal inglés y español...", cit., p. 291; y MORILLAS CUEVA, L., "Derecho Penal y deporte...", cit., p. 48 se manifiestan de forma similar.

93 Vid., por todos, RÍOS CORBACHO, J.M., Lineamientos de la violencia en el Derecho Penal del deporte..., cit., p. 259.

94 Tal como establecen, entre otras, las SSAP de Castellón de 22 de febrero de 2000; de Zaragoza 54/2012 de 18 de abril, [JUR/2012/178249], la cual condena por falta de lesiones por un cabezazo, puesto que entiende que desde el momento en el que se infringen las reglas, no cabe aplicar la causa de justificación del art. 20.7 CP; de Jaén (Sección $3^{\text {a }}$ ) 233/2017 de 5 de junio, [JUR/2017/220021]; y de Baleares de 10 de enero de 2018.

95 Y esto es así, porque el deportista no tiene derecho a practicar deporte con las reglas que desee imponer. MONROY ANTÓN, A.J., "El delito de lesiones en el deporte...", cit., p. 9. 
modalidad profesional o amateur. En este caso, entendemos que la causa de justificación del ejercicio legítimo de un oficio, derecho o cargo no tiene cabida para eximir de responsabilidad penal a las lesiones causadas por imprudencia grave, puesto que las mismas vulneran con especial intensidad lo establecido en la reglamentación deportiva ${ }^{96}$. Aun sin tener el agente intencionalidad lesiva, pudo haber previsto que su actuación causaría el resultado que finalmente tuvo lugar y no por ello cejó en su empeño. Por tanto, merece igual reproche penal que si hubiera sucedido en cualquier otro ámbito social. Pues bien, llegados a este punto y, para culminar, no siendo satisfactoria ninguna de las teorías enunciadas para eximir de responsabilidad penal en el caso de lesiones deportivas ocasionadas por imprudencia grave, plateamos su imputabilidad.

\subsubsection{Lesión intencionada sobrepasando la normativa deportiva}

Llegados a este punto, resta abordar lo que sucede con las lesiones deportivas causadas con dolo, es decir, con intención manifiesta e infracción clara de la reglamentación del deporte en cuestión ${ }^{97}$. Estas lesiones las ejecuta aquel que infringe un deber al aprovechar la situación y la cobertura de actuación dentro del marco de permisión de la regla, intencionadamente y con ocasión del juego pero fuera del mismo. Tal como plantea RÍOS CORBACHO, una cosa son las acciones deportivas ejecutadas durante el juego que pudieran tener relevancia penal y otra las acciones del deportista cuando no media lance ${ }^{98}$. Algunos ejemplos ilustrativos de este tipo de situaciones los constituyen la brutal patada que en 2009 propinó Sergio Jáuregui en el cuello a Leonardo Medina durante un partido de fútbol, por lo que este último tuvo que ser hospitalizado por las lesiones derivadas de tal agresión; o el cabezazo de Brandao a Thiago Motta en el túnel de vestuarios, provocándole una hemorragia y rotura del tabique nasal. Alejado del fútbol, en el boxeo, el caso de Kid Sullivan que impregnó sus guantes con tintura de belladona, cegando con ello a su adversario, Battling Nelson; o el mordisco de Mike Tyson a Evander Hollifield a quien seccionó parte del lóbulo. Pero no solo en deportes violentos o de contacto, incidentes similares también tienen lugar en otros en los que no se prevé dicho contacto físico entre contendientes. En este sentido, traemos a colación la espeluznante caída de Jakobsen durante el Tour de Polonia de 2020, provocada por Dylan Groenewegen al intentar impedir que aquel le adelantara en los metros finales. En vista de las características de las acciones anteriores, no cabe duda sobre su antijuridicidad, no existiendo causa de justificación alguna que permita excluir la responsabilidad del individuo, aunque hay quien considera que ciertas lesiones deportivas dolosas pueden excusarse a través de un supuesto consentimiento individual dentro del límite de la costumbre ${ }^{99}$. Para nosotros, tal planteamiento

96 De esta opinión, PAREDES CASTAÑÓN, J.M., "Consentimiento y riesgo en las actividades deportivas...”, cit., p. 654, para quien desde el momento en el que no se observan las normas de cuidado, no se puede hablar de ejercicio de un derecho, como tampoco cabe aplicar esta eximente para el ejercicio de la profesión en la imprudencia grave, pues los jugadores profesionales no pueden ampararse en un supuesto derecho a lesionar, emanado del ejercicio legítimo del oficio.

97 Dentro de este supuesto se incluye tanto el dolo directo como el eventual, muy cercano este último a la imprudencia porque el sujeto, aunque no tenga conocimiento y voluntad de ejecutar la acción lesiva, se representa como probable el resultado dañoso, de no necesaria producción y no querido directamente, a pesar de lo cual lo acepta de manera consciente al no renunciar a la ejecución de los actos. MORILLAS CUEVA, L., Sistema de Derecho Penal. Parte General..., cit., pp. 695 y 696.

98 RÍOS CORBACHO, J.M., Lineamientos de la violencia en el Derecho Penal del deporte..., cit., p. 267.

99 En este sentido, ESER, A., "Deporte y justicia penal...", cit., p. 61. EL MISMO en "Lesiones deportivas y Derecho Penal...", cit., p. 5. De forma similar, NAVAS RENEDO, B., "Las reglas del juego como límite de la intervención 
debe rechazarse inmediatamente, en tanto la lesión dolosa no vulnera solamente las reglas del deporte, sino que además quebranta lo establecido en el Código Penal por existir un concreto ánimo o intención de lesionar, suponiendo un aumento intolerable del riesgo que normalmente asume el individuo que decide practicar una determinada actividad deportiva, por lo que debe ser objeto de reproche penal ${ }^{100}$, debiendo responder el responsable por homicidio doloso, asesinato o lesiones dolosas ${ }^{101}$. Además, se confía en que el rival ajuste su conducta a lo establecido normativamente, por lo que no cabe pensar que en ningún caso pueda consentir en ser lesionado dolosamente, mediante una acción claramente intencional e irrespetuosa a las reglas y las mínimas exigencias de cuidado atribuidas al deportista medio, por lo que no cabe aplicar eximente alguna ${ }^{102}$.

El requisito fundamental de perseguibilidad de las lesiones deportivas se ha concretado en la existencia de animus laedendi ${ }^{103}$, es decir, la acción consciente y voluntaria orientada al menoscabo de la salud del contrincante, aunque la ocasión venga motivada por el entorno de la disputa y algún lance de la misma. En dichos términos se pronuncia buena parte de la jurisprudencia, como la SAP de Castellón de 22 de febrero de 2000, [JUR/2012/178249], de la que resulta un pronunciamiento condenatorio por falta de lesiones ( si bien hubiera sido más acorde a los hechos, la calificación por delito del art. 147.1 CP). El caso del que conoce el Tribunal deriva de un partido de fútbol sala, durante el cual el apelado agredió al apelante con un puñetazo en la cara, del que se derivó la rotura de nariz. Independientemente de que se produjera o no durante la competición deportiva, no puede entenderse que devino de un lance del juego por accidente, sin intencionalidad, sino fuera del mismo, en un momento en el que el balón no estaba en disputa, porque el apelante en el momento en el que fue derribado por una zancadilla del apelado, se levantó del suelo y, detenido el juego para ser ambos

del Derecho Penal...", cit., p. 336. Por su parte, DOMÍNGUEZ IZQUIERDO, E.M., "El consentimiento y relevancia penal en los resultados lesivos en los deportes de contacto eventualmente violentos...", cit., p. 166, no entiende el consentimiento como eximente sino como atenuante, con lo que se reduciría la pena pero en ningún caso constituiría una exención de responsabilidad.

100 RODRÍGUEZ-MOURULLO, A., y CLEMENTE, I., "Dos aspectos de Derecho Penal en el deporte...,", cit., p. 16. Igualmente, la SAP de Jaén (Sección 3a) 233/2017 de 5 de junio, [JUR/2017/220021], para un hecho calificado como delito de lesiones durante un partido de fútbol, en el que se propinó un cabezazo que derivó en lesiones que requirieron tratamiento médico-quirúrgico, sostiene que estamos ante una agresión extra deportiva que sobrepasa el riesgo permitido implícito en el deporte, por ser dolosa y el partido de fútbol solamente fue el escenario donde se concreta la intención de lesionar.

101 De esta opinión, BENÍTEZ ORTÚZAR, I.F., "Derecho Penal y deporte en España...", cit., pp. 161 y ss.

102 MORILLAS CUEVA, L., "Derecho Penal y deporte...", cit., p. 47; y DOMÍNGUEZ IZQUIERDO, E.M., "El consentimiento y la relevancia penal de los resultados lesivos en los deportes de contacto eventualmente violentos...", cit., p. 146. En esta línea se pronuncia además la SAP de Burgos (Sección 1ª) 384/2015 de 15 de octubre, [JUR/2015/250372], en la que se sostiene que la práctica de todo deporte no conlleva un consentimiento en sufrir lesiones dolosas. Este pronunciamiento aboga por la injerencia penal en los delitos de lesiones dolosas, calificando como tal la acción del futbolista que golpea en el ojo derecho a otro, causando lesiones. Y, ello en base a considerar que en un partido de fútbol, aunque se pueden producir lesiones derivadas de alguna jugada o situación, no significa que cualquier actuación dentro del terreno de juego quede fuera del Derecho Penal, el cual debe intervenir cuando no se trata de un lance del juego ejecutado mediante imprudencia, sino una lesión fuera del mismo (como es dar un puñetazo en el ojo), fruto de una agresión intencionada, estando claramente tipificada en el Código Penal. Así las cosas, el Tribunal plantea acertadamente que no puede aplicarse el principio de "lo que sucede en el campo se queda en el campo porque el comportamiento del acusado fue cualquier cosa menos una conducta deportiva y cumple con todas las exigencias del tipo penal aplicable".

103 MORILLAS CUEVA, L., "Derecho Penal y deporte...", cit., p. 46; VENTAS SASTRE, R., "Las lesiones en la práctica deportiva...”, cit., p. 85; y VALLS PRIETO, J., "La intervención del Derecho Penal en la actividad deportiva...", cit., p. 6. 
expulsados del campo, enfurecido e irritado, propinó el puñetazo, con evidente animus laedendi. El Tribunal condena finalmente por considerar que existió una concreta voluntad de lesionar, pues al fútbol sala no se juega con los puños lanzándolos contra el jugador contrario, sino con los pies y si se emplean aquellos en lugar de estos no cabe suponer que es con otra intención que atentar contra la integridad física del contrincante, al menos con dolo eventual ${ }^{104}$. Junto a la intencionalidad y, en estrecha conexión con la misma, además se viene a exigir que el incidente se ejecute sin relación alguna con el juego, tal como se pone de manifiesto en la SAP de Santa Cruz de Tenerife 308/2002 de 22 de marzo, [JUR/2002/141493], en la que queda acreditado que el acusado, con ánimo de menoscabar la integridad corporal del contrario, sin lance del juego, dado que el balón se estaba disputando en otra zona del campo, le dio un golpe con el codo en el ojo izquierdo, de lo que se derivaron lesiones que requirieron para su sanidad, además de primera asistencia facultativa, tratamiento médico o quirúrgico, quedando secuelas. En la resolución se expone que, por la intención del agresor, los resultados que producen y por ser ajenos a la exigencia del juego, merecen la intervención penal ${ }^{105}$. En caso contrario, cuando el suceso ha tenido lugar en un lance del juego, lo normal es que se absuelva por entenderse que no hubo intención de lesionar ${ }^{106}$.

Así las cosas, hemos de reseñar que el Derecho Penal ha de conocer las lesiones (o muertes) dolosas, porque el autor no ha vulnerado únicamente la normativa del deporte, sino también lo dispuesto en el Texto punitivo, por lo que ha de responder de su actuar ilícito, no pudiéndose aplicar ninguna eximente, salvo alguna atenuante, como la de arrebato u obcecación del art. 21.3 CP pero lo que sí es importante dejar claro es que nunca debe imponerse como criterio determinante la normalidad de la tensión o exaltación de ciertos acontecimientos deportivos $^{107}$; y la reparación del daño del art. 21 CP.

104 Otros pronunciamientos en idéntica línea, son las SSAP de Cádiz de 27 de julio de 2001, [ARP/2001/765]; y de Huesca (Sección $1^{\text {a }}$ ) 62/2004 de 26 de marzo, [JUR/2004/135780]

105 Otro ejemplo de tal situación es el que recoge la SAP de Zaragoza 58/2006 de 13 de marzo, [JUR/2006/190731], en la que se enjuicia el comportamiento de dos jugadores que intercambiaron golpes, incidente que queda fuera de toda previsión normativa, desarrollándose por los cauces de la legislación penal. También la SAP de A Coruña (Sección 1 $1^{\text {a }}$ ) 272/2017 de 8 de junio, [JUR/2017/183460], que enjuicia un puñetazo que tuvo lugar fuera de un lance del juego del fútbol, cuando el agraviado y el sujeto activo se dirigieron al portero para que sacase. Tras unas palabras, el acusado propinó un puñetazo en la cara al perjudicado, de lo que se derivaron lesiones que requirieron tratamiento médico. Tal incidente se califica como delito de lesiones del art. 147.1 $\mathrm{CP}$ por entenderse que existió intención de lesionar, si bien se aplica la atenuante de reparación del daño. Los puñetazos son una constante en la práctica del fútbol. Los mismos se condenan porque no se puede entender que derivan de un lance del juego, cuando al fútbol se juega con los pies y no con los puños al aire: véase, en este sentido, las SSAP de Pontevedra, (Sección 2a) 248/2017 de 18 de octubre, [ARP/2017/1352]. En la misma, incluso el Ministerio Fiscal llegó a calificar el resultado lesivo dentro de lo previsto en el art. 150 CP por pérdida de piezas dentarias, aunque finalmente se desestima y se condena por un delito básico de lesiones del art. 147.1 CP; de Madrid (Sección 1 1) 441/2017 de 26 de octubre, [JUR/2018/1100]; y Barcelona 76/2019 de 5 de febrero, [JUR/2019/147996]. Alejado del fútbol, en el rugby, la SAP de Barcelona (Sección 10ª) 477/2017 de 27 de junio, [JUR/2017/263475] condena como autor de un delito de lesiones del art. 147.1 CP al jugador que durante un partido amistoso, sin provocación previa y en una acción ajena al partido, con intención de menoscabar la integridad del demandante, le propinó un puñetazo en la cara, del cual derivaron lesiones que requirieron tratamiento médico para su curación, quedando como secuela la desviación del tabique nasal. Para el mismo deporte, también la SAP de Madrid (Sección 15ª) 88/2018 de 12 de febrero, [JUR/2018/123997], con idéntica calificación, esto es, condena por el art. 147.1 CP.

106 Vid., entre otras, la SAP de Valencia, (Sección 2a) 314/2018 de 18 de mayo, [JUR/2018/162133].

107 DOMÍNGUEZ IZQUIERDO, "El consentimiento y la relevancia penal de los resultados lesivos en los deportes de contacto eventualmente violentos...”, cit., p. 166. 


\section{CONCLUSIONES}

Las lesiones constituyen un resultado muy frecuente en la práctica deportiva, más aún en aquellas modalidades basadas en la violencia o el contacto físico entre jugadores. En estos casos, los reglamentos establecen el límite de su ejercicio, de modo que toda actuación que los sobrepase se considera antirreglamentaria, mereciendo la oportuna amonestación, pudiendo incluso, llegado el caso, a ser perseguida penalmente cuando la extralimitación del sujeto sea especialmente intensa y de ello se deriven resultados lesivos de entidad o se ponga en peligro severamente el bien jurídico tutelado. Sin embargo, la disciplina deportiva ha pretendido erigirse con potestad suficiente para dirimir estas cuestiones, negándole la entrada al Derecho Penal, incluso cuando la gravedad de la acción la haría merecedora de una pena proveniente de este ámbito. En vista del tradicional enfrentamiento entre el deporte y el Ordenamiento punitivo, a nuestro juicio, es necesario que coexistan, sobre todo en el caso que venimos analizando y no proclamarse la impunidad de toda lesión deportiva, pues el individuo que practicase una determinada actividad y lesionase a un contrincante, bajo el paraguas de la competición, podría esconder una verdadera voluntad criminal que, en ningún caso, puede quedar exenta de pena. Así, ésta debe imponerse únicamente cuando se conculque o ponga en peligro un bien jurídico fundamental (como ocurre con la salud y la vida) y el ataque sea de entidad suficiente para merecer el oportuno reproche punitivo, dejando al arbitrio de la disciplina deportiva las demás cuestiones que no reúnan las características indicadas; $y$, ello en base a los principios fundamentales que rigen el Derecho Penal, especialmente el de intervención mínima, subsidiariedad y ultima ratio, desplegando su eficacia solamente cuando los mecanismos previos han fracasado.

La cuestión más controvertida surge al tratar de concretar cuál de los dos sectores normativos es de aplicación a un incidente que puede ser conocido por ambos puesto que, en base al principio non bis in idem se proscribe la doble sanción cuando exista identidad de sujeto, hecho y fundamento, tal como se hace patente en el art. 38.1 LCVD. Ha de señalarse que en el deporte no existe identidad de fundamento en las sanciones provenientes de cada uno de los ámbitos señalados, puesto que cada una protege distintas cuestiones. Así, la disciplinaria va dirigida a salvaguardar el correcto desarrollo del encuentro, mientras que la penal tiende a proteger bienes jurídicos protegidos en el Texto punitivo, por lo que, en este caso, cabría aplicar una sanción disciplinaria y una penal al individuo que lesiona durante el transcurso de una práctica deportiva. Esta última afirmación no viene a significar que todo resultado lesivo deba ser perseguido penalmente, sino únicamente aquellos que revistan unos caracteres determinados porque lo contrario derivaría en una criminalización del deporte del todo inadmisible, en tanto cualquier resultado lesivo, siquiera nimio, podría ser acreedor de una pena, lo cual supondría una expansión excesiva e irracional del Derecho Penal.

De este modo, en supuestos en los que tenga lugar una lesión pero se ejecute sin infracción de la normativa deportiva, será suficiente la imposición de una sanción deportiva. La doctrina y la jurisprudencia han articulado una serie de construcciones teóricas para justificarlo, entre las que destacan la adecuación social, el riesgo permitido y el ejercicio de un derecho, oficio o cargo del art. 20.7 CP. Todas ellas presentan alguna carencia, motivo por el que algunos autores han propuesto planteamientos mixtos que combinan algunas de las anteriores. No obstante, consideramos que no son necesarios tales plan- 
teamientos en este caso concreto, pues el respeto a las reglas del juego ya actúa como un parámetro de licitud de la conducta. Cuestión distinta es la infracción de las reglas del juego que no produce lesión. En este sentido, se vuelve a propugnar la atipicidad de la conducta aludiendo a la ausencia de resultado, sancionándose por lo general en exclusiva en el ámbito federativo. Aunque en algunos casos esto deba ser así, entendemos que el Derecho Penal debería tener cabida, aparte de la amonestación deportiva que correspondiese, siempre y cuando el incidente reúna unos determinados requisitos: que tenga lugar fuera de un lance del juego, que objetivamente se observe intencionalidad del autor y se ponga en grave peligro el bien jurídico aunque, dado el caso, podría ser de aplicación alguna atenuante, como las derivadas de la excitación emocional del contexto en el que tiene lugar y la reparación del año (apartados tercero y quinto del art. $21 \mathrm{CP}$ ).

Por su parte, mayores dificultades plantean los supuestos imprudentes, al no merecer todos idéntica respuesta, pues existen distintas graduaciones. No obstante, aunque hay quien sostiene que toda imprudencia debe quedar impune, para nosotros, los casos leves han de conocerse únicamente por la disciplina deportiva porque se consideran una cuestión normal y frecuente del juego y suelen derivar del ímpetu de los participantes, a quienes se exige un nivel de diligencia menor que el habitual. De modo que, en base a la ausencia de intencionalidad lesiva y tener lugar durante una jugada común, la potestad sancionadora queda atribuida en exclusividad a la disciplina deportiva. Por su parte, la imprudencia grave, no debe resolverse de la misma manera porque supone una intensa violación de la normas más elementales de la debida diligencia y el desprecio más absoluto del deber de cuidado y, si bien suelen quedar extramuros del Derecho Penal, el mismo debe intervenir, pues al conculcarse seriamente la normativa que rige en una determina práctica, se sobrepasa en mucho el límite del riesgo tolerado, no nos encontramos ante una actuación socialmente adecuada aunque tenga lugar en el deporte y, difícilmente puede entenderse que el individuo lesionado consintiese en tan nefasto resultado, dado que lo esperado al participar en un encuentro deportivo es que los demás respeten la normativa o, que aun sobrepasándose, la vulneración sea ínfima. Idéntica respuesta que este último, merecen las lesiones dolosas, aquellas ejecutadas con intención manifiesta y evidente infracción de las reglas, siempre y cuando quede acreditado un concreto animus laedendi, por lo que no cabe aplicar ninguna eximente por el mero hecho de tener lugar en el deporte, como si éste legitimara cualquier actuación, dotándola de la más absoluta impunidad.

De modo que la disciplina deportiva y el Derecho Penal han de coexistir en completa armonía, quedando delimitados los supuestos en los que aquella es la única que puede desplegar sus efectos, inhibiéndose de actuar el Ordenamiento punitivo; y los demás en los que sí puede intervenir este último, sin que ello suponga una expansión excesiva e irracional del Ius puniendi estatal, pues es necesaria su intromisión para garantizar su función de protección de bienes jurídicos fundamentales, independiente de la actividad social en la que tenga lugar, en este caso, el deporte. 